\title{
MICROSTRUCTURAL CHARACTERIZATION OF YTTRIA- STABILIZED ZIRCONIA PLASMA-SPRAYED DEPOSITS USING MULTIPLE SMALL-ANGLE NEUTRON SCATTERING
}

\author{
A. J. ALLEN ${ }^{1} \uparrow$, J. ILAVSKY ${ }^{1,2}$, G. G. LONG ${ }^{1}$, J. S. WALLACE ${ }^{1}$, C. C. BERNDT ${ }^{3}$ and \\ H. HERMAN ${ }^{3}$ \\ ${ }^{1}$ Ceramics Division, National Institute of Standards and Technology, Gaithersburg, MD 20899, USA, \\ ${ }^{2}$ Department of Chemical Engineering, University of Maryland, College Park, MD 20742, USA and \\ ${ }^{3}$ Department of Materials Science and Engineering, State University of New York, Stony Brook, NY
} 11794, USA

( Received 9 February 2000; received in revised form 27 October 2000; accepted 31 October 2000 )

\begin{abstract}
Density, electron microscopy, elastic modulus, and small-angle neutron scattering studies are used to characterize the microstructures of yttria-stabilized zirconia plasma-sprayed deposits as a function of both feedstock morphology and annealing. In particular, anisotropic multiple small-angle neutron scattering data are combined with anisotropic Porod scattering results to quantify each of the three main porous components in these thermal barrier coating materials: intrasplat cracks, intersplat lamellar pores and globular pores. An inverse correlation between the volume of porosity and its surface area is confirmed for the as-sprayed deposits, as is a preferential annealing of intrasplat cracks at elevated temperatures. The average elastic modulus is correlated with the total void surface area while the elastic anisotropy is related more closely to the intersplat porosity. However, depending on the feedstock morphology, globular pores are also shown to play a surprisingly significant role in post-anneal deposit microstructures and properties. (C) 2001 Acta Materialia Inc. Published by Elsevier Science Ltd. All rights reserved.
\end{abstract}

Keywords: Plasma spray; Coating; Neutron scattering; Microstructure; Elastic modulus

\section{INTRODUCTION}

Plasma-sprayed ceramic deposits are widely applied in engineering practice as thermal barrier coatings (TBC) on substrates or as free-standing parts following their removal from substrates [1-4]. However, TBCs have engineering reliability problems that may limit the trustworthiness and value of the systems into which they are incorporated [1,5]. An incomplete understanding of the complex processing-microstructure-property relationships in plasma-spraying, together with an insufficient microstructural characterization of the spray deposits themselves, lies at the heart of these reliability problems. Much current application development is empirically-based with only a limited use of mathematical models [6].

Plasma-sprayed ceramic deposits possess a complicated microstructure formed by the successive impacts of semi-molten powder particles on a substrate [7]. On impact, they spread out and solidify rapidly into lamellar splats with cooling rates in the

$\dagger$ To whom all correspondence should be addressed. Tel. +1-301-975-5982; fax: +1-301-975-5334.

E-mail address: andrew.allen@nist.gov (A.J. Allen) range $10^{4}-10^{5} \mathrm{~K} \mathrm{~s}^{-1}$. This results in the build-up of high cooling stresses within the splats and the frequent appearance of metastable phases [8]. Additional stresses may arise because of the different thermal expansion coefficients of the deposit and the substrate. Frequently, such stresses are relieved by cracking or sliding of the splats. Elevated temperatures during service life cause further microstructural changes and long-term phase changes [9, 10].

Plasma-sprayed ceramic deposit microstructures are dominated by two anisotropic distributions of preferentially-oriented voids: intersplat lamellar pores and intrasplat cracks. There is also a broad size distribution of rounded globular pores [11]. Intersplat pores are mostly parallel to the substrate (perpendicular to the spray direction) whereas intrasplat cracks are mostly perpendicular to the substrate. Variability in these coexisting anisotropic distributions, and the closed nature of many of the voids, have limited the applicability of techniques such as image analysis [12] or mercury intrusion porosimetry [13]. However, the high penetrability of neutron beams within condensed matter has been exploited to characterize the representative microstructures of both the open and closed voids in plasma-sprayed 
deposits. Our previous work [14-22] has applied the small-angle neutron scattering (SANS) method of Porod surface characterization to differentiate between the surface area orientation distributions of the two anisotropic void populations.

In the present paper, we describe how anisotropic multiple small-angle neutron scattering (MSANS) studies can be used to determine the representative dimensions, porosities, and orientation distributions of the microstructural void components in plasmasprayed ceramic deposits. This is done in some detail because the application of MSANS analysis to anisotropic multicomponent microstructures has not been presented previously. The results of the MSANS analysis are compared with electron microscopy observations. When sufficient void anisotropy exists, a combination of anisotropic MSANS studies and SANS Porod surface area characterization, together with density measurements, makes feasible the separate parameterization of all three void populations including the globular pores. Using these methods to quantify the microstructural changes that arise from annealing, new insights are gained into the changes observed in the properties of annealed plasmasprayed ceramic deposits such as those revealed by elastic modulus measurement. Finally, we discuss how modulus measurements can be combined with SANS and MSANS studies to provide a more complete characterization of the microstructural changes that typically occur at elevated temperatures during the early service life of plasma-sprayed ceramic TBC deposits.

\section{EXPERIMENTAL PROCEDURE}

\subsection{Samples studied}

Two yttria-partially-stabilized zirconia feedstock powder materials were studied, each with 7-8\% yttria mass fraction to suppress transformations between the tetragonal zirconia phase and the low-density monoclinic phase during formation and subsequent thermal cycling of the plasma-sprayed deposits. One, prepared by the fused-and-crushed method and denoted FC (Amdry 142 from Sulzer Plasma Technik Inc., Troy, $\mathrm{MI} \dagger)$, contained dense irregular grains in the size range $40-115 \mu \mathrm{m}$. The other, prepared by a proprietary (HOSP) plasma-spheroidization process and denoted PS (SX233 from Osram Sylvania Inc., Danvers, MA), contained less dense globular particles in the size range $25-95 \mu \mathrm{m}$. The lower density was due to the existence of internal porosity within the PS particles.

The plasma-sprayed deposits were fabricated using a gas-stabilized spray system (F4+ system, Sulzer

$\dagger$ Information on commercial products is given for completeness and does not necessarily constitute or imply their endorsement by the National Institute of Standards and Technology.
Plasma Technik Inc., Troy, MI) at the Center for Thermal Spray Research, State University of New York, Stony Brook, NY. The spray nozzle diameter was $8 \mathrm{~mm}$, the powder injector diameter, $1.8 \mathrm{~mm}$, and the gun power was $500 \mathrm{~A}$ at $68 \mathrm{~V}$. The powder feed rate was $1.56 \mathrm{~kg} \mathrm{~h}^{-1}\left(26 \mathrm{~g} \mathrm{~min}^{-1}\right)$, the argon primary gas flow rate, $2.4 \mathrm{~m}^{3} \mathrm{~h}^{-1}$ (40 slpm), the hydrogen secondary gas flow rate, $0.60 \mathrm{~m}^{3} \mathrm{~h}^{-1}(10 \mathrm{slpm})$, and the argon carrier gas flow rate was $0.18 \mathrm{~m}^{3} \mathrm{~h}^{-1}$ (3 slpm). The spray distances between the torch nozzle and substrate were $90 \mathrm{~mm}$ for FC and $65 \mathrm{~mm}$ for PS, chosen because these spray distances gave the least dissimilar total porosities.

Deposits, $\approx 5 \mathrm{~mm}$ thick, were sprayed onto mild steel substrates covered with a thin $(<0.1 \mathrm{~mm})$ layer of arc-sprayed aluminum. The aluminum layer was then dissolved in $20 \% \mathrm{HCl}$ acid to obtain free-standing deposits. The samples were sectioned to final dimensions of around $5 \mathrm{~mm} \times 25 \mathrm{~mm} \times 3.8 \mathrm{~mm}$ using a low-speed diamond saw. Five FC and five PS samples were prepared for study in the as-sprayed condition, and also after annealing for $1 \mathrm{~h}$ at $1100^{\circ} \mathrm{C}$, $1200^{\circ} \mathrm{C}, 1300^{\circ} \mathrm{C}$ or $1400^{\circ} \mathrm{C}$. Each annealed sample was heated to and cooled from its furnace annealing temperature at a rate set to $600 \mathrm{~K} \mathrm{~h}^{-1}$ but cooling was slower than this below $400^{\circ} \mathrm{C}$.

The sample densities were determined geometrically after precision diamond cutting and grinding into tetragonal shapes. The precise orthogonal dimensions were measured by micrometer and each sample carefully weighed in air. From the densities given by the mass-over-volume ratios, total porosities, $\Phi_{T}$, were deduced to within a standard deviation of $\pm 0.1 \%$ by volume, based on the average of five independent density determinations in each case and an assumed theoretical density of $6.00 \mathrm{~g} \mathrm{~cm}^{-3}$ [8]. Accurate evaluation of $\Phi_{T}$, shown in Table 1, was essential for reliable microstructural characterization of the deposits by small-angle scattering.

\subsection{Porod (surface) small-angle neutron scattering characterization}

All of the small-angle neutron scattering (SANS) measurements were made on the 8-meter SANS

Table 1. Density, total porosity and total surface area results ${ }^{\mathrm{a}}$

\begin{tabular}{lccc}
\hline $\begin{array}{l}\text { Feedstock and } \\
\text { condition }\end{array}$ & $\begin{array}{c}\text { Density } \\
(\% \mathrm{TD})\end{array}$ & $\begin{array}{c}\text { Total porosity, } \\
\Phi_{T}(\%)\end{array}$ & $\begin{array}{c}\text { Total surface } \\
\text { area, } S_{\mathrm{T}}\left(\mathrm{m}^{2}\right. \\
\left.\mathrm{cm}^{-3}\right)\end{array}$ \\
\hline FC & & & \\
As-sprayed & $87.3(1)$ & $12.7(1)$ & $3.03(6)$ \\
$1100^{\circ} \mathrm{C} / 1 \mathrm{~h}$ & $87.6(1)$ & $12.4(1)$ & $2.42(5)$ \\
$1200^{\circ} \mathrm{C} / 1 \mathrm{~h}$ & $88.2(1)$ & $11.8(1)$ & $2.03(4)$ \\
$1300^{\circ} \mathrm{C} / 1 \mathrm{~h}$ & $88.6(1)$ & $11.4(1)$ & $1.67(3)$ \\
$1400^{\circ} \mathrm{C} / 1 \mathrm{~h}$ & $89.8(1)$ & $10.2(1)$ & $1.17(2)$ \\
$\mathbf{P S}$ & & & \\
$\mathrm{As}-\mathrm{sprayed}$ & $82.9(1)$ & $17.1(1)$ & $2.62(4)$ \\
$1100^{\circ} \mathrm{C} / 1 \mathrm{~h}$ & $84.1(1)$ & $15.9(1)$ & $2.16(3)$ \\
$1200^{\circ} \mathrm{C} / 1 \mathrm{~h}$ & $84.4(1)$ & $15.6(1)$ & $1.59(2)$ \\
$1300^{\circ} \mathrm{C} / 1 \mathrm{~h}$ & $85.3(1)$ & $14.7(1)$ & $1.36(2)$ \\
$1400^{\circ} \mathrm{C} / 1 \mathrm{~h}$ & $85.4(1)$ & $14.6(1)$ & $1.08(2)$ \\
\hline
\end{tabular}

${ }^{a}$ Standard uncertainties in least significant digits given in parentheses. 


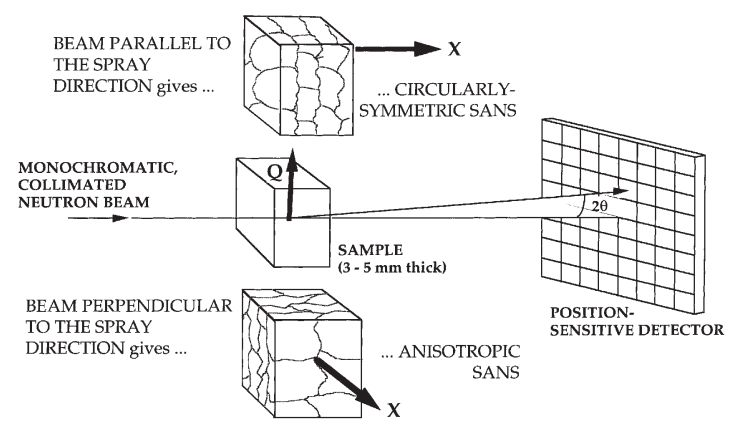

Fig. 1. Schematic for SANS experiments with the two sample orientations used. The spray direction, $\mathbf{X}$, is given for the two sample orientations. The direction of $\mathbf{Q}$ is given for the one scattered beam direction shown.

instrument [23] at the Center for Neutron Research, National Institute of Standards and Technology, Gaithersburg, MD. A monochromatic, collimated beam of neutrons with wavelength, $\lambda$, controlled by a neutron velocity selector, was passed through each parallel-sided sample. Scattered neutrons were recorded with a two-dimensional area detector. An experimental schematic is shown in Fig. 1 for the two different sample orientations used.

In plasma-sprayed ceramic deposits, the scattering arises from a difference, $|\Delta \rho|$, in the neutron scattering-length density, a fundamental measure of the neutron interaction with matter, at the interface between the voids and the solid splats. The absolute-calibrated scattered intensity or macroscopic differential scattering cross-section [24, 25], $\mathrm{d} \Sigma(\mathbf{Q}) / \mathrm{d} \Omega$, is a function of the magnitude $Q(=$ $[4 \pi / \lambda] \sin \theta$, where $2 \theta$ is the scattering angle) and direction of the scattering vector, $\mathbf{Q}$. Fig. 1 shows that $\mathbf{Q}$ lies in the scattering plane and is almost orthogonal to both the incident and small-angle scattered beams. In principle, $\mathrm{d} \Sigma(\mathbf{Q}) / \mathrm{d} \Omega$ is related to the porosity or volume fraction, $\Phi$, of the scattering voids, to their scattering contrast, $|\Delta \rho|^{2}$, with the surrounding material, and to their size, orientation and surface-area distributions, projected along $\mathbf{Q}$. In practice, the coarse and concentrated deposit microstructures preclude conventional SANS studies except for measuring the void surface areas from the Porod scattering at high $Q$ where $Q \Delta \geq 3$ and $\Delta$ is the opening dimension of the voids.

Porod scattering [24] measurements were made to determine the total surface area per unit volume, $S_{\mathrm{T}}$, of all of the open and closed voids in the sample microstructure. Symmetry in the microstructure about the spray direction enabled a complete anisotropic analysis to be performed from one Porod measurement on each sample oriented with the spray direction perpendicular to the incident neutron beam $[17,22]$. The beam diameter was $2.4 \mathrm{~mm}$, $\lambda=0.6 \mathrm{~nm}$, the wavelength resolution, $\Delta \lambda / \lambda=$
$15 \%$, and the sample-to-detector distance was 3.6 $\mathrm{m}$, giving a measured $Q$ range of $0.1-1.6 \mathrm{~nm}^{-1}$. The anisotropic scattered data were corrected for parasitic background scattering effects, calibrated against a silica scattering standard, and sector-averaged to give $\mathrm{d} \Sigma(\mathbf{Q}) / \mathrm{d} \Omega$ data vs $\mathbf{Q}$ in $10^{\circ}$ increments about the incident beam position on the instrument detector. The apparent Porod surfaces were evaluated over a typical $Q$ range of $0.3-1.2 \mathrm{~nm}^{-1}$, depending on the $\mathbf{Q}$ direction.

Anisotropic Porod scattering, described in detail elsewhere [17], strongly amplifies the true anisotropy in the surface area orientation distribution of the deposits. This is important for distinguishing the different anisotropic void distributions. For example, for a single population of spheroids, monodispersed in shape, size and orientation, of aspect ratio, $\beta$, and orthogonal radii, $R_{\mathrm{O}}, R_{\mathrm{O}}, \beta R_{\mathrm{O}}$, the anisotropy in the Porod scattering $[26,27]$ is proportional to $1 / \beta^{4}$. Such extreme anisotropy in the scattering depends critically on the shape and orientation of the scattering voids, and is not easily related to the true pore surface area orientation distribution. However, an orientational average of the Porod scattering (at given $Q$ ) for $\mathbf{Q}$ directions taken over all solid angle with respect to the sample spray direction, can be used to determine the total void surface area:

$$
\underset{Q \rightarrow \infty}{\operatorname{Limit}}\left\langle\frac{\mathrm{d} \Sigma(\mathbf{Q})}{\mathrm{d} \Omega}\right\rangle=\frac{2 \pi|\Delta \rho|^{2} S_{\mathrm{T}}}{Q^{4}}
$$

where $\langle\mathrm{d} \Sigma(\mathbf{Q}) / \mathrm{d} \Omega\rangle$ implies an orientational average. As with the total porosity, $\Phi_{T}$, an accurate value for the total (open and closed) void surface area within each sample, $S_{\mathrm{T}}$, determined using equation (1) and shown in Table 1, was found to be essential for an unambiguous microstructural characterization of each deposit.

\subsection{Multiple small-angle neutron scattering charac- terization}

Internal surface area characterization is important for quantifying plasma-sprayed microstructures but the information obtained from Porod scattering alone is incomplete. For many materials other SANS methods can complement the surface area information by providing representative sizes and volume fractions of the void component morphologies. For plasma-sprayed deposits the large void dimensions $(0.1-10 \mu \mathrm{m})$ cause the Porod scattering to extend throughout the $Q$ range of most SANS instruments at neutron wavelengths shorter than $0.8 \mathrm{~nm}$. At longer wavelengths the high void concentrations result in copious multiple scattering. Fortunately, in recent years the MSANS technique has been developed [2833] and applied to recover some of this structural and volumetric information [34-36].

The MSANS formalism (see Appendix A for a summary of the algebraic functions used) predicts the 
MSANS beam-broadening vs wavelength and was originally developed to extract microstructural parameters from the broadening associated with concentrated ensembles of coarse, spherical scatterers [2830]. It has been progressively enhanced to treat: randomly-oriented spheroids [31-33], anisotropicallyoriented oblate spheroids (e.g., cracks), and now multi-component systems containing two anisotropic distributions of cracks or planar pores co-existing with a globular pore population.

Following our previous analysis [28-33] the overall profile in $\mathbf{Q}, W\left(\mathbf{Q} \mid \tau_{\mathrm{s}}\right)$, of the neutron beam is considered [28] after it has progressed through a sample thickness, $\tau_{\mathrm{s}}$. The profile $W\left(\mathbf{Q} \mid \tau_{\mathrm{s}}\right)$ is related to the measured beam-broadening by:

$$
r_{\mathrm{c}}=\underset{Q \rightarrow 0}{\operatorname{limit}}\left[-\frac{W^{\prime \prime}\left(\mathbf{Q} \mid \tau_{\mathrm{s}}\right)}{W\left(\mathbf{Q} \mid \tau_{\mathrm{s}}\right)}\right]^{-1 / 2}
$$

$W^{\prime \prime}\left(\mathbf{Q} \mid \tau_{\mathrm{s}}\right)$ represents a double-differential with respect to $\mathbf{Q}$ and the parameter, $r_{\mathrm{c}}$, is effectively the "radius of curvature" of the shape of the beam profile in $\mathbf{Q}$ at zero $Q$. Although unmeasureable directly, $r_{\mathrm{c}}$ is experimentally a measure of the width of the beambroadening and is numerically equal to the standard deviation of a Gaussian fitted to the beam profile at low $Q$. Thus, $r_{\mathrm{c}}$ has the same units as $Q$. The variation of $r_{\mathrm{c}}$ with $\lambda$ has provided a more tractable analysis for obtaining the mean scatterer size than has analysis of the broadened beam profile at just one $\lambda$ value [34-36].

For a microstructure that is axially-symmetric about the incident beam direction, the scattering is circularly-symmetric and Moliere's theory of multiple scattering (in the form of transport equation used by Bethe) can be applied to describe the beam profile as it passes through condensed matter. If $k=2 \pi / \lambda$, the volume-weighted mean radius of the scatterers is $R_{\mathrm{O}}$, the mean number of multiple scatters within the sample is $\bar{z}$, and $J_{\mathrm{O}}(x)$ denotes a zero order Bessel function, it has been shown [28-31] that:

$$
W\left(Q R_{\mathrm{O}} \mid \tau_{\mathrm{s}}\right)=\frac{k^{2} R_{\mathrm{O}}^{2}}{2 \pi} \int_{0}^{\infty} \zeta J_{\mathrm{O}}\left(Q R_{\mathrm{O}} \zeta\right) \exp [-\bar{z}\{1-q(\zeta)\}] \mathrm{d} \zeta
$$

where $\zeta$ is a dimensionless integration variable. While the integrals must be evaluated numerically, the realspace function, $q(\zeta)$, is related to the single-scattering intensity by:

$$
q(\zeta)=\frac{2 \pi}{k^{2} \Sigma_{T}} \int_{0}^{\infty} J_{\mathrm{O}}\left(Q R_{\mathrm{O}} \zeta\right)\left\langle\frac{\mathrm{d} \Sigma\left(Q, v_{\mathrm{O}}\right)}{\mathrm{d} \Omega}\right\rangle_{\text {ORIENT }} Q \mathrm{~d} Q
$$

where, for an axially-symmetric microstructure about the incident beam direction, $\Sigma_{T}$ is the total scattering cross-section per unit sample volume, i.e., $\Sigma_{T}=$ $n \sigma_{\mathrm{T}}$ where $\sigma_{\mathrm{T}}$ is the mean total scattering cross-section per scatterer, $n$ is the number density of scatterers in the sample, and $\bar{z}=\Sigma_{T} \tau_{\mathrm{s}}=n \sigma_{\mathrm{T}} \tau_{\mathrm{s}}$. The term $\left\langle\mathrm{d} \Sigma\left(Q, v_{\mathrm{O}}\right) / \mathrm{d} \Omega\right\rangle_{\text {ORIENT }}$ is the average single-scatter SANS cross-section per unit sample volume taking into account the axially-symmetric microstructure orientation distribution (see Appendix A). The parameter, $v_{\mathrm{O}}$, is a phase parameter given by $v_{\mathrm{O}}=$ $2 R_{\mathrm{O}}|\Delta \rho| \lambda$, and indicates that the multiple scattering from coarse features is affected both by diffraction and by refraction [28]. Only when $v_{\mathrm{O}} \ll 1$ can refraction effects be ignored.

For a plasma-sprayed ceramic deposit sample oriented with the spray direction parallel to the incident neutron beam (see Fig. 1), the microstructure is axially-symmetric about the spray direction and the above conditions hold (i.e., the MSANS is circularly-symmetric). For an orthogonal sample orientation the anisotropic MSANS data can be circularly-averaged about the incident beam direction. This is equivalent to circularly-averaging the orientation distributions of the intrasplat cracks and intersplat pores to give an effective axially-symmetric microstructure about the incident beam that is nevertheless not the same as when the sample is oriented with the spray direction parallel to the beam. Thus, $\sigma_{\mathrm{T}}, \Sigma_{T}, \bar{z},\left\langle\mathrm{~d} \Sigma\left(Q, v_{\mathrm{O}}\right) / \mathrm{d} \Omega\right\rangle_{\text {ORIENT }}$, $\mathrm{q}(\zeta)$ and $W\left(Q R_{\mathrm{O}} \mid \tau_{\mathrm{s}}\right)$ are all different for the two sample orientations.

With known $\Phi_{T}$, together with known $\Sigma_{T}$ and average single-scatter SANS cross-section, $\left\langle\mathrm{d} \Sigma\left(Q, v_{\mathrm{O}}\right) / \mathrm{d} \Omega\right\rangle_{\text {ORIENT }}$, for each of the two sample orientations used, equations (2)-(4) can be used in principle to extract a representative radius, $R_{\mathrm{O}}$, from the circularly-averaged MSANS broadening, $r_{\mathrm{c}}$, as a function of $\lambda$ [28-33] [see Fig. 2(a)]. In practice, a functional form of $\left\langle\mathrm{d} \Sigma\left(Q, v_{\mathrm{O}}\right) / \mathrm{d} \Omega\right\rangle_{\text {ORIENT }}$ must be found that takes into account the anisotropic multicomponent void microstructures. In this connection, we assume the intrasplat crack and intersplat pore void spaces to comprise separate networks of oblate spheroidal volume elements with, respectively, volume-weighted mean radii $R_{\mathrm{OC}}$ and $R_{\mathrm{OP}}$, mean aspect ratios $\beta_{\mathrm{C}}$ and $\beta_{\mathrm{P}}$, and porosities $\Phi_{C}$ and $\Phi_{P}$. We assume the globular pores to be spheres with mean radius, $R_{\mathrm{OG}}$, and porosity, $\Phi_{G}$.

For spheroidal elements oriented with their $\beta R_{\mathrm{O}}$ axes at an angle $\eta$ with respect to $\mathbf{Q}$, it has been shown previously for the single-scatter SANS crosssection that [31]:

$$
\frac{\mathrm{d} \Sigma_{\beta}\left(Q, v_{\mathrm{O}}\right)_{X}}{\mathrm{~d} \Omega}=n\left|f_{\beta}\left(Q, v_{\mathrm{O}}\right)_{X}\right|^{2}
$$




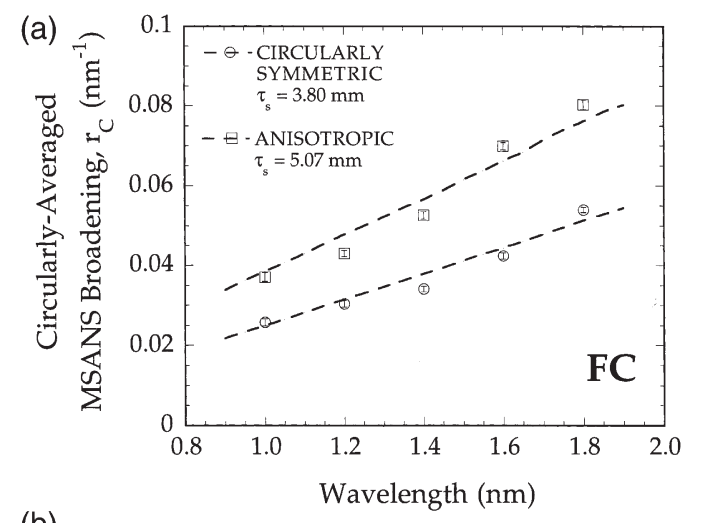

(b)

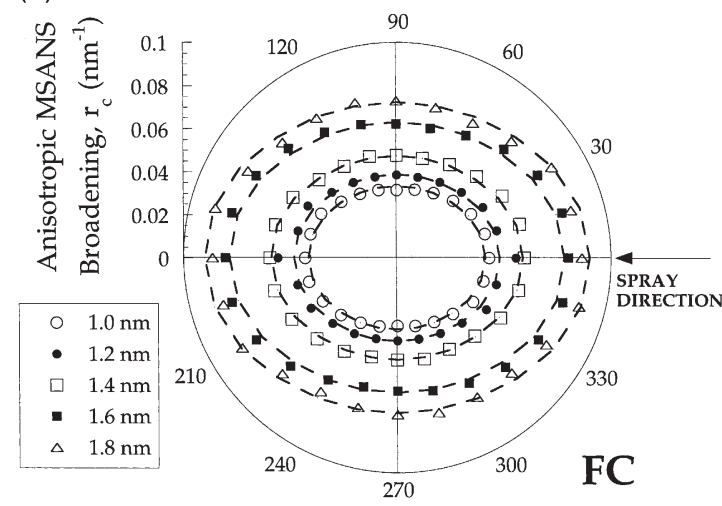

Fig. 2. MSANS broadening data (symbols) with model fits (lines) for as-sprayed FC deposit: (a) circularly-averaged MSANS $r_{\mathrm{c}}$ vs $\lambda$ for both sample orientations; and (b) anisotropic angular variation of MSANS $r_{\mathrm{c}}$ at different $\lambda$, for sample oriented with the spray direction perpendicular to the incident beam.

$$
\begin{gathered}
f_{\beta}\left(Q, v_{\mathrm{O}}\right)_{X} \\
=i k R_{\mathrm{O}}^{2} K(\beta, X) \int_{0}^{1} J_{\mathrm{O}}\left(Q R_{\mathrm{O}} K(\beta, X) \xi\right)\{1 \\
\left.-\exp \left[\frac{i \beta v_{\mathrm{O}} \sqrt{1-\xi^{2}}}{K(\beta, X)}\right]\right\} \xi \mathrm{d} \xi
\end{gathered}
$$

where $n=3 \Phi / 4 \pi \beta R_{\mathrm{O}}^{3}, K(\beta, X)=\left[1+\left(\beta^{2}-1\right) X^{2}\right]^{1 / 2}$, $X=\cos (\eta)$, and $\xi$ is a dimensionless integration parameter (different from $\zeta$ in the derivation of the multiply-scattered beam profile). Also, the total scattering cross-section for spheroid orientation, $X$, is given by [31]:

$$
\Sigma_{\beta, X}=\frac{3 \Phi}{4 \pi \beta R_{\mathrm{O}}^{3}} \sigma_{\beta, X} \text { where } \sigma_{\beta X}=\pi R_{\mathrm{O}}^{2} A(\beta, X)
$$

with

$$
A(\beta, X)=K(\beta, X)\left\{2+\frac{4}{c^{2}}[1-\cos (c)-c \sin (c)]\right\}
$$

and $c=\beta v_{\mathrm{O}} / K(\beta, X)$. With either sample orientation, both $\mathrm{d} \Sigma_{\beta}\left(Q, v_{\mathrm{O}}\right)_{X} / \mathrm{d} \Omega$ and $\Sigma_{\beta, X}$ must be averaged over the separate spheroidal-element orientation distributions (with respect to $\mathbf{Q}$ ) for the intrasplat cracks and intersplat pores, and summed together with the contribution from the globular pores to give $\left\langle\mathrm{d} \Sigma\left(Q, v_{\mathrm{O}}\right) / \mathrm{d} \Omega\right\rangle_{\text {ORIENT }}$ and $\Sigma_{T}$.

To perform the orientational averaging, the approximate orientation distributions for the cracks and the intersplat pores are separately parameterized in terms of the probability weights-over-random of finding the short $\left(\beta R_{\mathrm{O}}\right)$ axes of their oblate spheroidal elements (the local crack- or pore-normals) within $30^{\circ}$ of the spray direction, $30-60^{\circ}$ from the spray direction, or $60-90^{\circ}$ from it. These weights, $p_{\mathrm{L}}, p_{\mathrm{M}}$ and $p_{\mathrm{H}}$, respectively, are normalized to unity with respect to an integration over all possible solid angles for each void system, giving: $0.134 p_{\mathrm{L}}+$ $0.366 \mathrm{p}_{\mathrm{M}}+0.500 p_{\mathrm{H}}=1$. (For a random distribution, $p_{\mathrm{L}}=p_{\mathrm{M}}=p_{\mathrm{H}}=1$.) For MSANS measurements with the spray direction parallel to the incident beam, these weights give the orientation distribution about the incident beam directly. For the circularly-averaged anisotropic MSANS data obtained with the spray direction perpendicular to the beam, a transformation is necessary to give the probability weights-over-random of finding the short $\left(\beta R_{\mathrm{O}}\right)$ axes in corresponding angular ranges with respect to the incident beam direction, rather than the spray direction. Equations (5) and (6) can then be numerically-averaged over these two different axially-symmetric orientation distributions. To orientationally-average the SANS cross-sections, an angular mesh size of $0.0025 \pi$ radians is used for both the azimuthal and polar angles with respect to the incident beam, and the angle, $\eta$, with respect to $\mathbf{Q}$ calculated at each orientation. The direction of $\mathbf{Q}$ is approximated to lie within the plane of the sample.

Equations (3) and (4) must be expressed in terms of a representative microstructural radius, and it was found convenient to make this the intrasplat crack radius, $R_{\mathrm{OC}}$. However, the SANS cross-section, $\left\langle\mathrm{d} \Sigma\left(Q, v_{\mathrm{O}}\right) / \mathrm{d} \Omega\right\rangle_{\text {ORIENT }}$ in equation (3), combines the scattering from all three void components as do $\Sigma_{T}$ and $\bar{z}$ in equation (4). Thus, while $\left\langle\mathrm{d} \Sigma\left(Q, v_{\mathrm{O}}\right) / \mathrm{d} \Omega\right\rangle_{\text {ORIENT }}$ depends only on $R_{\mathrm{OC}}$ as an independent parameter, it incorporates assumed relative volume fractions of the three void components, size ratios $\left(R_{\mathrm{OP}} / R_{\mathrm{OC}}\right.$ and $\left.R_{\mathrm{OG}} / R_{\mathrm{OC}}\right)$, spheroidal element aspect ratios $\left(\beta_{\mathrm{C}}\right.$ and $\left.\beta_{\mathrm{P}}\right)$ and orientational weights $\left(p_{\mathrm{L}}, p_{\mathrm{M}}\right.$ and $\left.p_{\mathrm{H}}\right)$ for each of the crack and intersplat pore networks. Also, $\Sigma_{T}=\Sigma_{C}+\Sigma_{P}+\Sigma_{G}$ with the subscripts $\mathrm{C}, \mathrm{P}$ and $\mathrm{G}$ denoting the intrasplat crack, intersplat pore and globular pore components, respectively. Finally, equation (3) must be evaluated at $Q=0$ and doubly-differentiated with respect to $Q$, allowing $r_{\mathrm{c}}$ to be obtained at a given $\lambda$ using equation (2).

In principle for a given independently-measured $\Phi_{T}, R_{\mathrm{OC}}$ can be determined from the experimentally 
measured $r_{\mathrm{c}}$ vs $\lambda$ by inversion of equations (2)-(4). Since the crack and intersplat pore networks are sufficiently anisotropic and distinct from each other to give significantly different circularly-averaged MSANS broadening for the two sample orientations studied, the microstructural parameters can be adjusted until consistency is achieved between the $R_{\mathrm{OC}}$ values obtained from the MSANS model fitting in the two sample orientations. Unfortunately, these $r_{\mathrm{c}}$ vs $\lambda$ variations, alone, are insufficient to determine the microstructure, uniquely, and two further constraints must be introduced. One of these is that the combined surface area of the three void components must be equal to $S_{\mathrm{T}}$, measured independently by Porod scattering. The other constraint is to require consistency with the anisotropy actually observed in the MSANS beam-broadening [shown in Fig. 2(b)] when the sample spray direction is oriented perpendicular to the incident neutron beam.

It is not possible to model the anisotropy in the MSANS broadening directly using equations (3) and (4) because of the requirement for axial symmetry about the incident beam direction. However, for one population of oblate spheroidal elements with orientation $X$, equation (5) predicts [37] that the width of the single-scatter profile in $Q$ is proportional to $\left[R_{\mathrm{O}} K(\beta, X)\right]^{-1}$ in the diffraction limit of $v_{\mathrm{O}} \ll 1$. This means that the degree of anisotropy in the scattering is proportional to $1 / \beta$ and is (inverse) linearly related to the anisotropy in the microstructure. It is assumed that the anisotropy in the MSANS beam-broadening follows this single-scattering anisotropy. The MSANS anisotropy for each of the two anisotropic void populations is calculated by numerically-averaging the $1 / K(\beta, X)$ anisotropy factor over the orientation distribution with respect to any one direction of $\mathbf{Q}$ in the sample plane. This process is repeated for all azimuthal $\mathbf{Q}$ directions around the incident beam while applying the same sector-averaging as used in the anisotropic MSANS data collection. The overall predicted anisotropy is then deduced from a weighted average of the sector-averaged component anisotropy factors for the intrasplat cracks, intersplat pores and globular pores (where the anisotropy factor is just unity). The weighting is proportional to $\Sigma_{C} / R_{\mathrm{OC}}, \Sigma_{P} / R_{\mathrm{OP}}$ and $\Sigma_{G} / R_{\mathrm{OG}}$, respectively, to take into account both the different component contributions to $\Sigma_{T}$ and the different single-scatter profile widths arising from differences among $R_{\mathrm{OC}}, R_{\mathrm{OP}}$ and $R_{\mathrm{OG}}$. Required consistency between the predicted and measured MSANS anisotropies was found to be the additional constraint needed for obtaining an unambiguous microstructure from the MSANS studies.

In summary, the objective in the anisotropic MSANS analysis is to determine those porosities, $\Phi$, radii, $R_{\mathrm{O}}$, spheroidal aspect ratios, $\beta$, and orientation distributions, which satisfy the following four constraints within the experimental uncertainties: (i) component porosities consistent with the total porosity, $\Phi_{T}$ determined from density measurements; (ii) component surface areas (using standard expressions for a spheroid) consistent with the total surface area, $\mathrm{S}_{T}$, determined from Porod scattering; (iii) fits to the circularly-averaged MSANS $r_{\mathrm{c}}$ vs $\lambda$ data consistent for the two sample orientations used; and (iv) prediction of the MSANS anisotropy consistent with that observed in the $r_{\mathrm{c}}$ data with the spray direction perpendicular to the incident beam.

Major approximations in the analysis are that each anisotropic microstructural void component comprises oblate spheroidal elements with a constant (modest) aspect ratio, and that each void component is represented by a volume-weighted mean size. However, since the largest scattering profile width is for $\mathbf{Q}$ parallel to the short $\left(\beta R_{\mathrm{O}}\right)$ axis of a spheroid, the contribution to the MSANS broadening from each anisotropic void component is characterized mainly by the mean opening dimension, $\langle$ O.D. $\rangle$, given by $\langle$ O.D. $\rangle=4 \beta R_{\mathrm{O}} / 3$. Thus, the $\langle$ O.D. $\rangle$ values for the intrasplat cracks and intersplat pores, together with the globular pore diameter $\left(2 R_{\mathrm{OG}}\right)$, are the main dimensions of physical significance given by the analysis. Electron microscopy suggests that, apart from occasional coarse features, volume-weighted mean values for these dimensions are representative of the microstructural void components present.

As a tool in the mathematical analysis, suitable values of $\beta$ were found from experimentation to be 0.1 for the spheroidal elements representing the intrasplat cracks and 0.2 for those representing the intersplat pores. These values are much less extreme than the mean macroscopic crack or intersplat-pore aspect ratios, defined as the ratio of the respective $\langle$ O.D. $\rangle$ to the crack or intersplat-pore "mean penny diameter" (the large planar dimension of either of these void systems traced through any tortuosity present). The latter aspect ratios cannot be determined from MSANS alone but can be estimated by combining the MSANS analysis with anisotropic elastic modulus measurement as discussed later.

In the present study, the MSANS broadening was measured for each as-sprayed and annealed ceramic deposit sample oriented both with the incident beam parallel to the spray direction and perpendicular to it. The beam profile was measured at wavelengths of $1.0,1.2,1.4,1.6$ and $1.8 \mathrm{~nm}$ for the samples and for the incident beam. These wavelengths were sufficiently long, and the samples sufficiently thick, to produce copious beam-broadening, i.e., $\bar{z}$ was always greater than $\sim 5$. Each $r_{\mathrm{c}}$ value was obtained as the standard deviation of a Gaussian fitted to the beam profile in the intensity range from $\sim 95 \%$ of the maximum (at $Q=0$ ) down to $\sim 40 \%$ of the maximum. Previous studies have established that this fit regime provides reliable determinations of $r_{\mathrm{c}}$ from the broadening [34-36]. For the spray direction perpendicular to the incident beam, the anisotropic MSANS was evaluated by sector-averaging the data on the two-dimensional area detector in $15^{\circ}$ sectors 
around the incident beam. Given the above constraints, the normalization requirement for the orientational weights, the selected $\beta$-values, measured $r_{\mathrm{c}}$ values at five $\lambda$ values for each sample orientation, and the significant MSANS anisotropies observed for the deposits studied, estimated fractional uncertainties in the MSANS-derived component parameters were $\pm 10 \%$ for the porosities, and $\pm 5 \%$ for the surface areas, 〈O.D.〉's, and mean globular pore diameters.

\subsection{Electron microscopy}

Scanning electron microscopy (SEM) studies were carried out to provide basic microstructure evaluation, and to validate some of the trends seen in the SANS and MSANS analyses. During polishing, a number of artifacts (pull-outs) were created that were difficult to distinguish from the voids. Thus, a quantitative image analysis was not attempted on these samples.

For each of the 10 samples (see Table 1), two orthogonal surfaces were prepared for SEM, one parallel and one perpendicular to the substrate plane. The surfaces were prepared by diamond sawing, coarse grinding with a Grid-Abade disk (TBW Industries, Furlong, PA) to obtain flat surfaces, polishing for 1520 min with MasterPolish II (Buehler Ltd., Lake Bluff, IL) at 250 RPM with a force of approximately $200 \mathrm{kPa}$, and sputter-coated with $15 \mathrm{~nm}$ of $\mathrm{Au}-\mathrm{Pd}$. With magnifications ranging from $1 \mathrm{kX}$ to $5 \mathrm{kX}$, an Amray 1830 SEM system (Amray Inc., Bedford, MA) was used to obtain (mainly) back-scattered SEM images of the void microstructures in the deposits. Some of these are presented in Fig. 3.

\subsection{Elastic modulus measurement}

The elastic modulus was measured for each sample, both along the spray direction and within the substrate plane. These measurements were carried out on the same sample surfaces studied by SEM, but prior to sputtering the Au-Pd layer. The main purpose was to correlate the anisotropic mechanical properties of the plasma-sprayed deposits with their microstructures, as a function of feedstock morphology and annealing treatment. The present studies were developed from earlier modulus measurements of similar plasma-sprayed ceramic deposits $[38,39]$.

Each elastic modulus was measured using modified commercial indentation equipment to which load and displacement measuring sensors had been added. Indentation loading/unloading curves were recorded to a precision of $3 \mathrm{mN}$ ( $0.3 \mathrm{~g}$-force) and displacements to $10 \mathrm{~nm}$. The polished surfaces of the samples were indented with a spherical $2.381 \mathrm{~mm}$ (3/32 in.) diameter WC sphere and a nominal 4-N load, resulting in a contact diameter between the WC sphere and the sample of approximately $50 \mu \mathrm{m}$ and a peak elastic penetration depth of approximately 2.5 $\mu \mathrm{m}$. The apparent elastic modulus of the sample, $E_{\mathrm{APP}}$, was calculated from the load-displacement curve using standard Hertzian contact theory [38]. The modulus of the sample, $E_{\mathrm{S}}$, could be calculated from $E_{\mathrm{APP}}$ by taking into account the elastic properties of the spherical indenter:

$$
E_{\mathrm{S}}=\frac{1-\mu_{\mathrm{S}}^{2}}{\left\{\frac{1}{E_{\mathrm{APP}}}-\frac{\left(1-\mu_{\mathrm{I}}^{2}\right)}{E_{\mathrm{I}}}\right\}}
$$

where $\mu$ is Poisson's ratio, and the subscripts, I and $S$, refer to the indenter and sample, respectively. It was assumed that $\mu_{\mathrm{S}}=0.2, \mu_{\mathrm{I}}=0.22$, and $E_{\mathrm{I}}=$ $614 \mathrm{GPa}$.

The elastic modulus of the sample was calculated from a least-squares fit of the $L^{2 / 3}$ versus $h$ data from the loading curve where $L$ was the load and $h$ the depth of elastic penetration of the spherical indenter. This relationship was linear throughout the loading range examined, indicating elastic behavior. Deviations from elastic Hertzian contact behavior (e.g., due to cracking) would have resulted in deviations from linearity. From measurements on standard glass samples, estimated fractional uncertainties in the measured moduli were $\pm 0.5 \%$.

Indentation measurements made with the indenter impinging normal to each deposit top surface were used to derive an effective Young's modulus, $E_{\mathrm{S}}=$ $E_{\mathrm{SPRAY}}$, parallel to the spray direction. Measurements with the indenter impinging normal to each deposit section cut perpendicular to the substrate were used to derive an effective Young's modulus, $E_{\mathrm{S}}=$ $E_{\text {PLANE}}$, within the substrate plane. The major aim was to relate the absolute values of $E_{\mathrm{SPRAY}}$ and $E_{\mathrm{PLANE}}$, together with the elastic anisotropy given by the ratio, $E_{\mathrm{PLANE}} / E_{\mathrm{SPRAY}}$, to the component void microstructures determined from MSANS. In addition, theoretical analyses exist in the literature [40-42], that allowed estimates to be made of the macroscopic "penny" diameters of the intrasplat cracks and intersplat pores by combining the anisotropic modulus data with the MSANS-derived parameters already obtained.

\section{RESULTS AND DISCUSSION}

\subsection{Densities, porosities and surface areas}

Table 1 presents the measured percentage theoretical densities (\% TD) and derived total porosities for the 10 plasma-sprayed yttria-stabilized zirconia ceramic deposit samples. Also listed are the total void surface areas, per unit sample volume, determined from an orientational average of the anisotropic Porod scattering over all solid angles, as given by equation (1). The statistical standard uncertainties shown were determined as part of the Porod equation fits to the data in the appropriate $Q$ range. An over (under)-estimate of the skeletal density (100\% TD) would have resulted in an over (under)-estimate of the total porosities, and an under (over)-estimate of the total surface areas derived from the Porod scattering. How- 

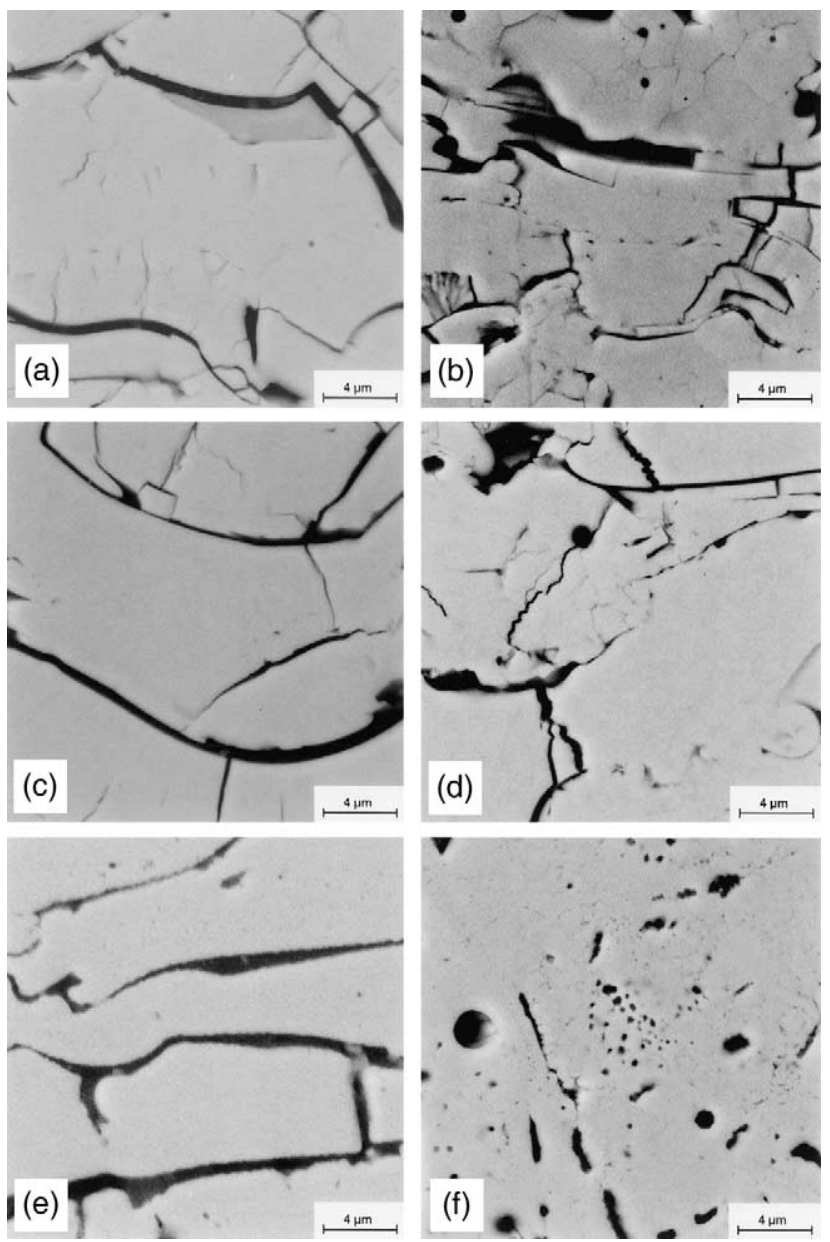

Fig. 3. SEM back-scattered electron images of plasma-sprayed deposit polished sections, oriented with the spray direction vertical, for: as-sprayed deposits, (a) FC and (b) PS; annealed $1100^{\circ} \mathrm{C} / 1 \mathrm{~h}$ deposits, (c) $\mathrm{FC}$ and

(d) PS; annealed $1400^{\circ} \mathrm{C} / 1 \mathrm{~h}$ deposits, (e) $\mathrm{FC}$ and (f) PS.

ever, the value used, $6.00 \mathrm{~g} \mathrm{~cm}^{-3}$, was deduced from the known feedstock composition and agreed with the results of a recent neutron diffraction study on the same materials [8].

Table 1 shows that the higher porosity in the spheroidized PS feedstock material, compared to that in the FC feedstock, is reflected in the porosities of the ceramic deposits themselves. Even after annealing for $1 \mathrm{~h}$ at $1400^{\circ} \mathrm{C}$, the PS deposit is still more porous than the FC deposit in the as-sprayed state. In spite of this, the as-sprayed FC deposit has the greater total void surface area, and its surface area remains slightly higher than that of the PS deposit for corresponding annealing treatments. In both systems, the 60\% decrease in surface area on annealing is considerably more marked than the $15-20 \%$ fractional decrease in porosity.

The apparent surface area orientation distributions derived from the Porod scattering strongly amplify the true microstructural anisotropies [25-27] within the deposits and are an important guide to changes during annealing. For example, in the as-sprayed FC system, the intrasplat crack and intersplat pore components could be discerned clearly, and the cracks were observed to anneal out preferentially during the heat treatments [22]. These trends can now be compared with the quantitative results derived from the MSANS studies.

\subsection{Microstructures of the as-sprayed deposits}

For the FC feedstock deposit in the as-sprayed condition, Fig. 2(a) presents best fits to the MSANS circularly-averaged broadening $r_{\mathrm{c}}$ vs $\lambda$ data obtained for the two sample orientations used (see Fig. 1), subject to the constraints discussed previously. Figure 2(b) presents corresponding fits, for the several $\lambda$ values used, to the anisotropies in $r_{\mathrm{c}}$ data obtained with the sample spray direction perpendicular to the incident neutron beam. Table 2 provides a summary of results obtained for the mean crack and pore sizes, as well as for the porosities and surface areas of each of the three void components in the FC and PS as-sprayed microstructures. The intrasplat crack and intersplat pore $\langle$ O.D. $\rangle$ values are close to those that would be obtained from the surface-to-volume ratios assuming parallel-sided cracks and pores. The estimated stan- 
Table 2. MSANS model fit results for the as-sprayed microstructures ${ }^{\mathrm{a}}$

\begin{tabular}{|c|c|c|c|c|}
\hline $\begin{array}{l}\text { Feedstock and void } \\
\text { component }\end{array}$ & Porosity (\%) & Surface area $\left(\mathrm{m}^{2} \mathrm{~cm}^{-3}\right)$ & $\begin{array}{c}\text { Mean opening dimension, } \\
\langle\text { O.D. }\rangle(\mu \mathrm{m})\end{array}$ & Mean pore diameter $(\mu \mathrm{m})$ \\
\hline \multicolumn{5}{|l|}{ FC } \\
\hline Intrasplat cracks & $2.9(5)$ & $1.26(7)$ & $0.048(3)$ & - \\
\hline Intersplat pores & $6.9(5)$ & $1.58(9)$ & $0.096(6)$ & - \\
\hline Globular pores & $2.9(4)$ & 0.19 (4) & - & $0.93(6)$ \\
\hline \multicolumn{5}{|l|}{ PS } \\
\hline Intrasplat cracks & $4.1(3)$ & $1.27(7)$ & $0.068(3)$ & - \\
\hline Intersplat pores & $6.7(4)$ & $1.09(5)$ & $0.136(5)$ & - \\
\hline Globular pores & $6.3(5)$ & $0.26(4)$ & - & $1.53(6)$ \\
\hline
\end{tabular}

${ }^{a}$ Estimated standard uncertainties in least significant digits given in parentheses.

dard uncertainties in the parameters given in Table 2 were deduced by varying the computer model fits to the MSANS $r_{\mathrm{c}}$ vs $\lambda$ data, subject to the previously discussed constraints for $\Phi_{T}, S_{\mathrm{T}}$, and MSANS anisotropy [see Fig. 2(b)].

Additional uncertainties arose from the simplifying assumptions made for the component microstructures. In particular, single volume-weighted mean values were assumed for the dimensions of each void type, whereas all of these void components have extended size distributions. Generally, the $R_{\mathrm{O}}$ values for the spheroidal elements that were used to model the intrasplat cracks and intersplat pores could be set equal to one another, implying that the cracks $(\beta=0.1)$ have about half the opening dimension of the intersplat pores $(\beta=0.2)$. The mean globular pore radii are coarser: about $1.3 R_{\mathrm{O}}$ for the $\mathrm{FC}$ system, and $1.5 R_{\mathrm{O}}$ for the PS system. The derived values for the mean void dimensions, given in Table 2, reflect these relationships. The results in Table 2 suggest that a coarser microstructure of the PS system is responsible for a smaller total surface area than in the FC system. The greater total porosity in PS is mainly accounted for by greater globular porosity.

Although the orientational distributions of the intrasplat cracks and intersplat pores were each represented by just three orientational weights, this was sufficient to model the MSANS anisotropies shown in Fig. 2(b). The orientational weights determined for the two feedstock systems are given in Table 3 . Again, the estimated standard uncertainties were determined by varying the MSANS model fits subject to the constraints. Table 3 indicates that the intrasplat cracks and intersplat pores are more anisotropically distributed in the FC than in the PS system.
Figure 3 presents SEM images of the deposit microstructures for the FC and PS deposits, in the assprayed condition, and annealed at $1100^{\circ} \mathrm{C}$, and $1400^{\circ} \mathrm{C}$. All of the sample microstructures showed regions of considerable variability, resulting from the stochastic nature of the plasma-spray process. The assprayed FC and PS deposit microstructures shown are fairly similar. The mainly horizontal splats are outlined by the intersplat pores, and some finer, mainly vertical, intrasplat cracks are visible inside the splats. While intersplat pores coarser than those indicated in Table 2 are seen, the finer ones have opening dimensions not inconsistent with the $\langle$ O.D. $\rangle$ values predicted by MSANS. The intrasplat cracks in the SEM images are finer still, and their opening dimensions are also broadly consistent with the MSANS predicted 〈O.D.〉 values. While it was not possible to discern a coarser PS microstructure here, other differences between the FC and PS deposits, predicted by MSANS, are apparent in the SEM images. Both the cracks and intersplat pores are better aligned in the FC deposit, and the intersplat pores account for a larger fraction of the porosity. Overall, the appearance of the SEM-imaged microstructures shows qualitative agreement with the quantitative MSANS analysis.

\subsection{Microstructural changes after annealing}

Figures 4, 5, and 6 present the results derived from a full MSANS study of all of the samples, measured using the two sample orientations. Similar experimental uncertainties apply to the data in these figures as are given in the Tables. Figure 4 presents the data on the total and void component porosities vs $1-\mathrm{h}$ annealing temperature for the two feedstock systems. Figure 5 presents the corresponding surface area

Table 3. Orientational probability weights-over-random for intrasplat cracks and intersplat pores with respect to the angle (low, medium, high) between their normals and the spray direction ${ }^{\mathrm{a}}$

\begin{tabular}{llllll}
\hline $\begin{array}{l}\text { Feedstock and } \\
\text { condition }\end{array}$ & Crack $p_{\mathrm{L}}$ & Crack $p_{\mathrm{M}}$ & Crack $p_{\mathrm{H}}$ & Pore $p_{\mathrm{L}}$ & Pore $p_{\mathrm{M}}$ \\
\hline FC (all conditions) & $0.02(1)$ & $0.35(8)$ & $1.74(8)$ & $3.79(9)$ & $1.14(5)$ \\
PS (as-sprayed, & $0.05(3)$ & $0.62(8)$ & $1.54(5)$ & $2.88(6)$ & $1.44(4)$ \\
$\left.1100^{\circ} \mathrm{C}, 1200^{\circ} \mathrm{C}\right)$ & $0.17(2)$ & $0.77(3)$ & $1.39(3)$ & $2.26(4)$ & $0.15(4)$ \\
PS $\left(1300^{\circ} \mathrm{C}\right)$ & $0.18(3)$ & $0.78(2)$ & $1.38(2)$ & $2.15(3)$ & $1.25(3)$ \\
PS $\left(1400^{\circ} \mathrm{C}\right)$ & & & & $0.48(2)$ \\
\hline
\end{tabular}

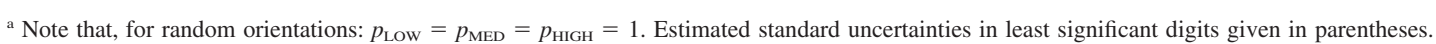


(a)

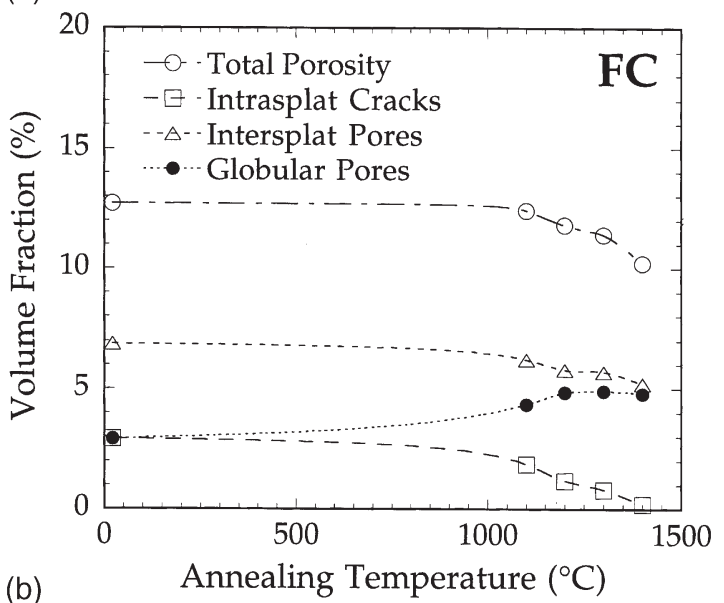

(b)

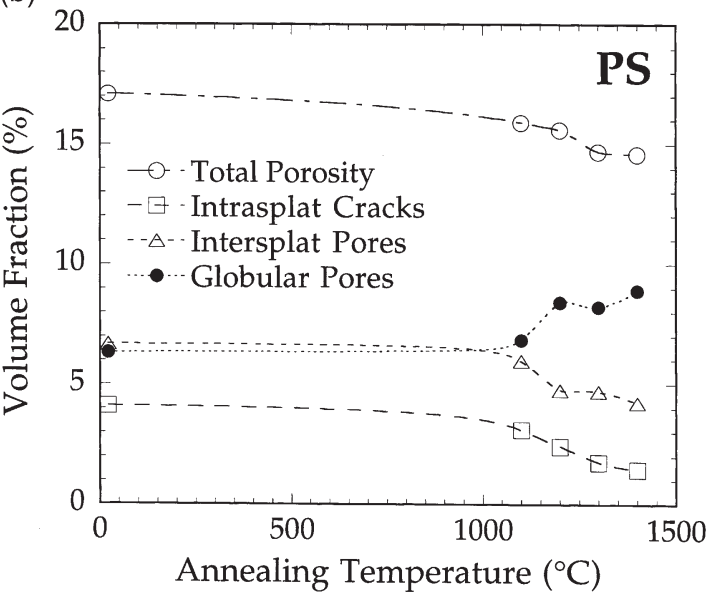

Fig. 4. Porosities vs annealing temperature for: (a) FC and (b) PS deposits. As-sprayed temperature taken as: $21^{\circ} \mathrm{C}$. Lines are guides to the eye.

changes, and Fig. 6 presents the data on the mean void dimensions. (The macroscopic penny diameters of the intrasplat cracks and intersplat pores, shown in Fig. 6, were deduced by combining the MSANS analysis with anisotropic elastic modulus measurements and will be discussed later.) At the annealing temperatures used, both the FC and PS deposits exhibit a modest reduction in total porosity, a marked reduction in total void surface area, and a modest coarsening in most of the microstructure. Also, intrasplat cracks are preferentially annealed out at lower temperatures than are the intersplat pores, as discussed in previous work [19-22]. However, a comparison of Figs 4, 5 and 6, with the SEM images of Fig. 3, indicates some striking differences in the microstructural responses of the FC and PS deposits to annealing.

In the FC deposit, the annealing out of the intrasplat cracks, and the persistence after annealing of the intersplat pores, are evident from their residual porosities and their residual surface areas. The preferred alignments of the intrasplat cracks and intersplat pores were also found to persist (Table 3).
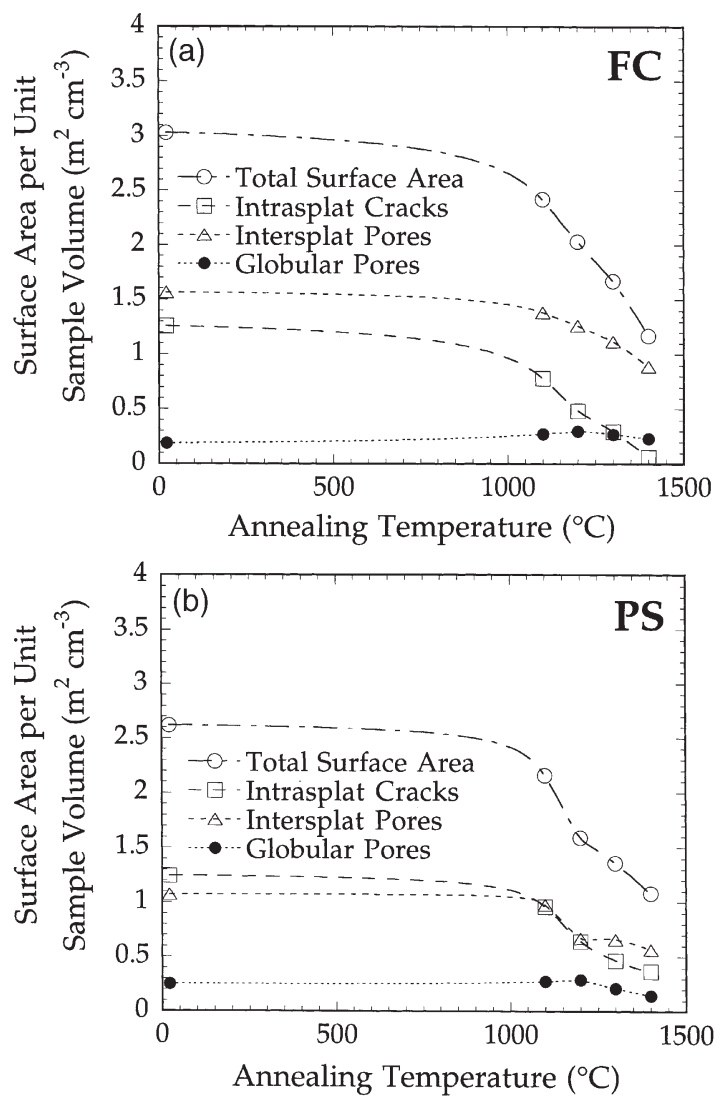

Fig. 5. Surface areas vs annealing temperature for: (a) FC and (b) PS deposits. As-sprayed temperature taken as $21^{\circ} \mathrm{C}$. Lines are guides to the eye.

As shown in Fig. 3(a, c, e), SEM supports these results of the MSANS analysis for the FC microstructure annealed for $1 \mathrm{~h}$ at $1100^{\circ} \mathrm{C}$ and $1400^{\circ} \mathrm{C}$. Figures 4(a), 5(a), and 6(a) suggest that a conversion of the intrasplat cracks to globular or irregular-shaped pores occurs during annealing, and that the latter coarsen slightly to $\sim 1.25 \mu \mathrm{m}$. It was not possible to confirm this trend in the SEM micrographs shown. The globular or irregular pores seen elsewhere in the FC deposit showed a broad size distribution, with many pores in the $\sim 1-\mu \mathrm{m}$ size regime.

In the PS deposit, fewer intrasplat cracks anneal out at lower annealing temperatures $\left(1100^{\circ} \mathrm{C}\right.$ and $1200^{\circ} \mathrm{C}$ ), there is a more significant loss of intersplat pores, and some reduction in the preferred alignments of these two void types (Table 3). Figures 4(b), 5(b), and $6(\mathrm{~b})$, suggest a considerable transformation of intrasplat cracks (and intersplat pores) to globular pores occurs, which coarsen to $3.5 \mu \mathrm{m}$ at higher annealing temperatures $\left(1300^{\circ} \mathrm{C}\right.$ and $\left.1400^{\circ} \mathrm{C}\right)$. These effects of annealing can be associated with observed reductions in both the magnitude and anisotropy of the MSANS broadening of the incident neutron beam, in the absence of proportionate reductions in the total porosities. The MSANS-based results are also supported by the SEM micrographs for the PS deposit shown in Fig. 3(b, d, f), where a broad size distri- 
(a)

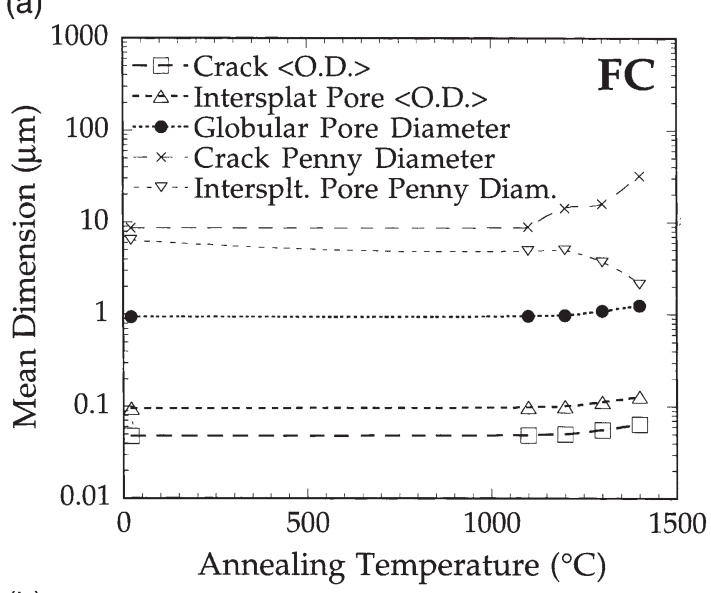

(b)

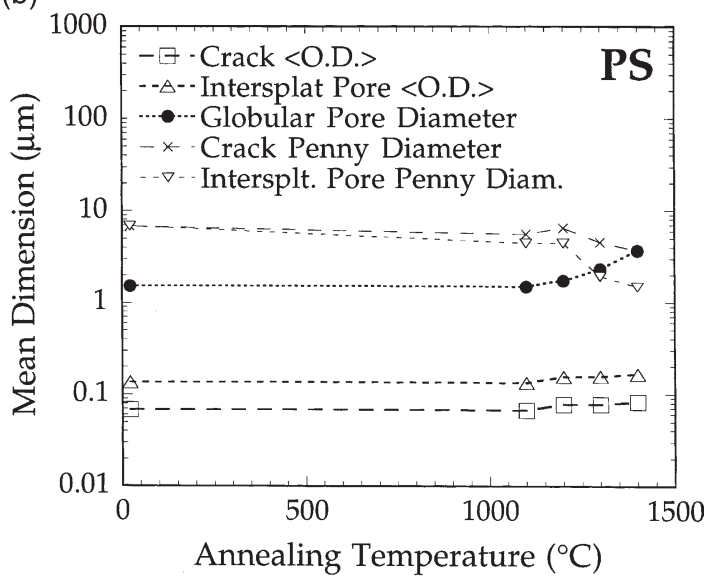

Fig. 6. Mean opening dimensions, 〈O.D.〉, and penny diameters for intrasplat cracks and intersplat pores, and mean globular pore diameters vs annealing temperature for: (a) FC and (b) PS deposits. As-sprayed temperature taken as $21^{\circ} \mathrm{C}$. Lines are guides to the eye.

bution of globular and irregular-shaped pores are observed to emerge, especially after the $1400^{\circ} \mathrm{C}$ anneal. A possible explanation is that the low density and hollow particles of the PS feedstock cause air or spray gases to become entrapped within the splats during spraying. The entrapped gas then leads to the development and coarsening of the many spherical pores observed after annealing. Other effects may include the coarse intrasplat crack (associated with a spherical pore) and the fine, unfused particle, both apparent in Fig. 3(d) for the $1100^{\circ} \mathrm{C}$ anneal.

By applying Porod scattering theory to the anisotropically-oriented spheroidal elements defined above $[26,27]$, anisotropic Porod surface distributions were derived for the multi-component MSANS model microstructures. For the highly-aligned FC microstructure, recovery of the observed anisotropic Porod surface distributions was precluded by the sensitivity of anisotropic Porod scattering to details of the actual shapes of the scattering voids. However, successful recovery of the observed anisotropic Porod surface distributions was achieved for the less-well aligned
PS microstructure, and is shown in Fig. 7 for the assprayed deposit. While this is further validation of our MSANS approach, it should be noted that Porod scattering studies alone would not have identified the critically different role of the volumetric globular pores in the two systems, or the different evolution during annealing of the relative intrasplat crack and intersplat pore volume fractions. Some annealing effects are visible in the SEM images, but it was the introduction of MSANS studies that yielded the statistically-representative microstructural parameters relevant to the prediction of deposit properties.

\subsection{Relationship of MSANS-derived microstructure to elastic properties}

Figure 8 presents the elastic moduli, $E_{\mathrm{SPRAY}}$ and $E_{\text {PLANE }}$, determined from indentation studies on all of the deposit samples. The measured moduli are much less than the Young's modulus of zirconia, $E_{\mathrm{O}}=$ $210 \mathrm{GPa}$ [39], due to the void structures within the deposits. The low value of $E_{\text {SPRAY }}$ is attributable to the population of intersplat pores aligned mainly parallel to the substrate, while that of $E_{\mathrm{PLANE}}$ is attributable to the intrasplat crack population (and to misaligned intersplat pores). The values of $E_{\mathrm{SPRAY}}$ and $E_{\text {PLANE }}$ increase as intrasplat cracks and intersplat pores anneal out at elevated temperatures, while the elastic anisotropy, given by the ratio, $E_{\mathrm{PLANE}} / E_{\mathrm{SPRAY}}$, decreases as shown in Fig. 9. A comparison of Fig. 9 with the earlier figures suggests that, of the MSANSderived microstructural parameters, the elastic anisotropy tracks most closely with the intersplat pores (surface areas recalled in Fig. 9). Thus, these pores should provide a quantifiable measure of the lamellar pore/splat structures that govern the anisotropic deposit properties.

The use of anisotropic elastic modulus measurement for the microstructural characterization of plasma-sprayed ceramic deposits has recently been discussed [40-42]. To illustrate using the approach of

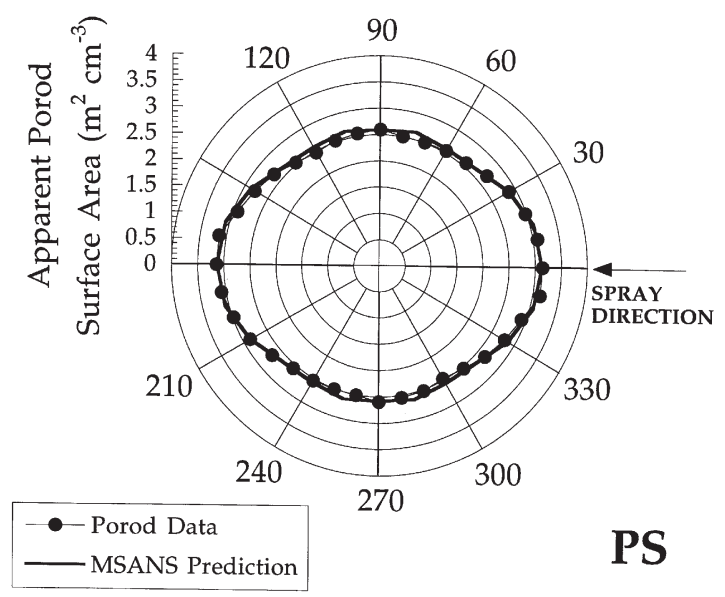

Fig. 7. Experimental anisotropic Porod surface orientation distribution with MSANS-model prediction for the as-sprayed PS deposit. 

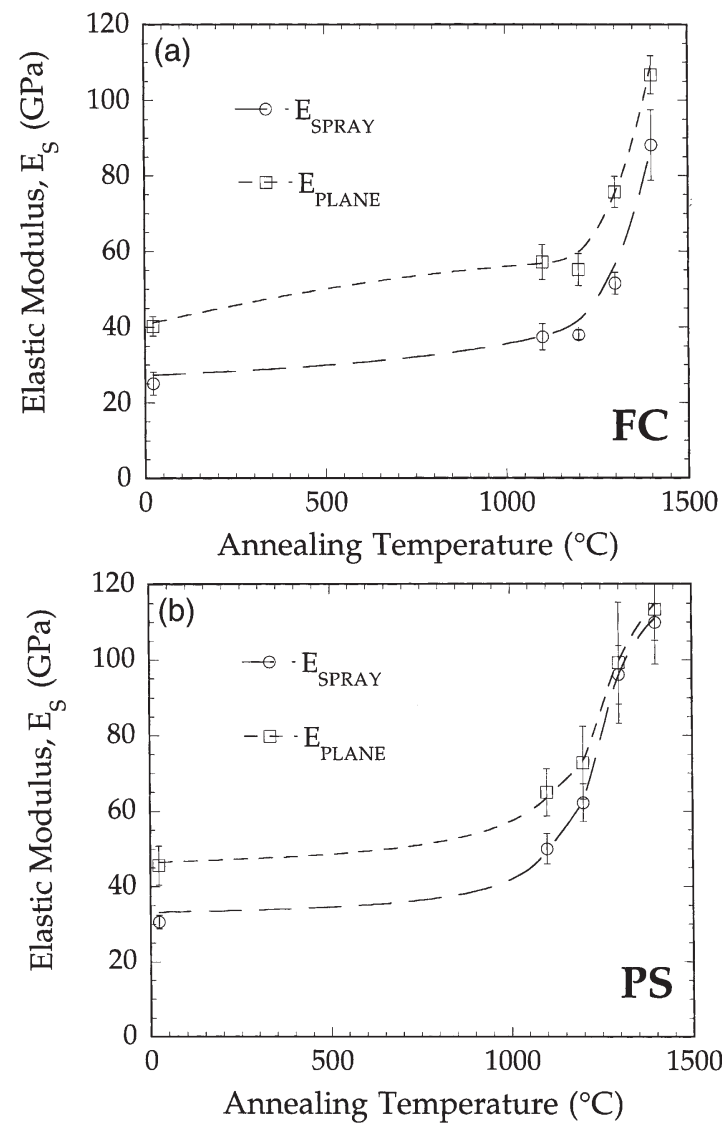

Fig. 8. Indentation elastic moduli along the spray direction, $E_{\mathrm{SPRAY}}$, and within the substrate, $E_{\mathrm{PLANE}}$, vs annealing temperature for: (a) FC and (b) PS deposits. As-sprayed temperature taken as $21^{\circ} \mathrm{C}$. Lines are guides to the eye.

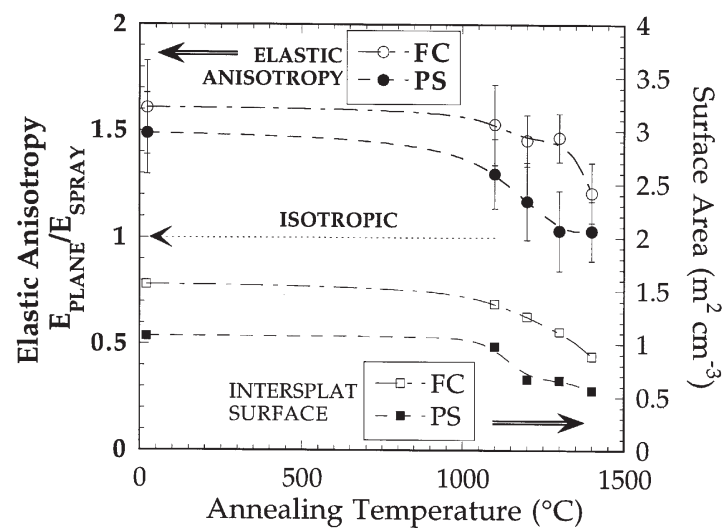

Fig. 9. Elastic anisotropy, $E_{\mathrm{PLANE}} / E_{\mathrm{SPRAY}}$, vs annealing temperature. Intersplat surface areas shown for comparison. Assprayed temperature taken as $21^{\circ} \mathrm{C}$. Lines are guides to the eye.

Kroupa and Kachanov [41, 42], the intrasplat cracks and intersplat pores are assumed to be aligned perpendicular and parallel, respectively, to the substrate plane. The anisotropic moduli, $E_{\mathrm{SPRAY}}$ and $E_{\mathrm{PLANE}}$, can then be related separately to $E_{\mathrm{O}}$ (above), to $\mu_{\mathrm{S}}$ (defined earlier), to the overall porosity, $\Phi_{T}$, and to the scalar densities, $d_{\mathrm{C}}$ and $d_{\mathrm{P}}$, respectively, of the intrasplat cracks and intersplat pores. These are defined by: $d_{\mathrm{C}}=\Phi_{C} /\left(4 \pi \alpha_{\mathrm{C}} / 3\right)$ and $d_{\mathrm{P}}=$ $\Phi_{P} /\left(4 \pi \alpha_{\mathrm{P}} / 3\right)$, where $\Phi_{C}$ and $\Phi_{P}$ are the respective MSANS-derived component porosities, and $\alpha_{\mathrm{C}}$ and $\alpha_{\mathrm{P}}$ are the macroscopic crack and intersplat-pore aspect ratios. Here, the $\alpha$-values are assumed to be the ratio of the appropriate $\langle$ O.D. $\rangle$ to the pennyshaped crack or pore diameter, in contrast to the $\beta$ values of the spheroidal elements defined previously.

From the analysis of the anisotropic elastic moduli [41, 42], $\alpha_{\mathrm{C}}$ and $\alpha_{\mathrm{P}}$ can be determined, in principle, and used to obtain the penny diameters because the 〈O.D.〉 values are already known from the MSANS analysis. The penny diameters so obtained are included in Fig. 6. For the as-sprayed FC and PS deposits, both the inferred intrasplat-crack and intersplat-pore penny diameters are in the range 6-8 $\mu \mathrm{m}$, acceptably close to the uninterrupted crack and pore lengths seen in Fig. 3( $a$ and $b)$. On annealing, Fig. 6 indicates a marked reduction in the intersplatpore penny diameters to $1.5-2.0 \mu \mathrm{m}$ after the $1400^{\circ} \mathrm{C}$ anneal, while the $\langle$ O.D.〉's increase slightly as previously discussed. Intersplat pores this short are consistent with Fig. 3(f) for the PS deposit. They are not consistent with Fig. 3(e) for the FC system, but short, partially sintered, intersplat pores were seen elsewhere in the annealed FC microstructure. This spheroidization of intersplat pores during annealing would be one of the expected effects of sintering. In the annealed PS deposits, the intrasplat cracks spheroidize in a broadly similar manner but, in the annealed FC deposits, the penny diameters deduced from this analysis actually get larger-a result not confirmed by SEM or by any other result. The assumptions underlying this analysis break down here because misaligned intersplat pores, rather than the largely annealed-out cracks, govern the value of $E_{\text {PLANE }}$ in the annealed FC deposits.

Despite the differences in the FC and PS microstructures, the modulus variations show some universal behavior. Figure 10 is a plot of the geometricmean elastic modulus, $\langle E\rangle$, given by $\langle E\rangle=$ $\left(E_{\mathrm{PLANE}} E_{\mathrm{PLANE}} E_{\mathrm{SPRAY}}\right)^{1 / 3}$, vs the total surface area per unit sample volume (from Porod scattering) for all of the samples studied. The calculated curve was deduced from the combined anisotropic MSANS and elastic modulus analysis. For these two deposit systems, sprayed under the same conditions of temperature and humidity, the mean elastic modulus is monotonically related to the total surface area, itself dominated by the overall concentration of planar voids.

\section{CONCLUSIONS}

In this paper, it has been shown how MSANS studies, in combination with Porod scattering, SEM, and density determination, can be used to obtain a quantitative representation of the different void components within plasma-sprayed ceramic deposits. The distinct 


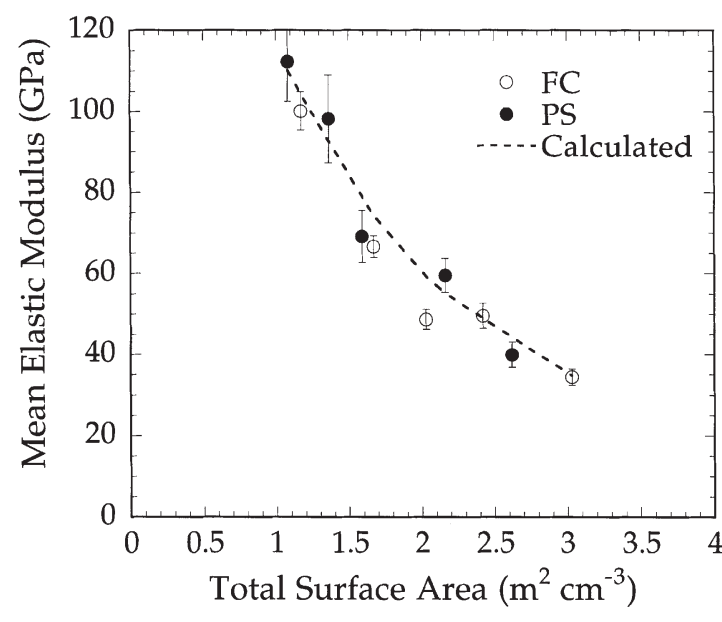

Fig. 10. Mean elastic modulus data, with predicted theoretical curve, vs total surface area per unit sample volume, $S_{\mathrm{T}}$, for all samples studied.

anisotropies of the intrasplat cracks and intersplat pores are the keys to this nondestructive, statisticallyrepresentative, microstructure characterization. Absolute porosities and surface areas of the void components, the mean opening dimensions and globular-pore diameter, as well as the approximate intrasplat-crack and intersplat-pore orientation distributions, have all been extracted from the analysis. As far as we are aware, this is the first time that the individual void components have been characterized in this way.

The generic differences between FC and PS plasma-sprayed deposit microstructures have been quantified and correlated with the feedstock morphology. FC deposits have a higher density and retain the splat/intersplat-pore structure to higher annealing temperatures. PS deposits have a lower density, but also a lower surface area and a higher elastic modulus. Differences in the anisotropic elastic moduli can be understood in terms of these differences in the plasma-sprayed microstructures, particularly in the intersplat pore systems. Since the annealing temperatures here are typical of present and envisaged operating temperatures for plasma-sprayed ceramic deposits in TBC applications, these studies indicate that TBC durability can be enhanced by adjusting the feedstock morphology to optimize the TBC mechanical property evolution during early service life, subject to structure-property relationships like that shown in Fig. 10.

In addition to the MSANS-derived parameters, a combination of anisotropic MSANS studies and elastic modulus measurements can be used to extract the penny diameters of the intrasplat cracks and intersplat pores. Further research is needed to relate the measured elastic moduli to the component void microstructures, by incorporating more realistic orientation distributions of the intrasplat cracks and intersplat pores [43]. A complete set of representative microstructural parameters (porosities, surface areas, 〈O.D.〉's, globular and penny diameters, and orientation distributions), for the void components of plasmasprayed ceramic deposits, is highly desirable. With appropriate assumptions for polydispersity in the microstructure, these parameters can be used to predict the generic processing-microstructure-property relationships, not only for the mechanical properties but also for other important TBC properties such as the dielectric permittivity and thermal conductivity.

Acknowledgements-We thank J. Barker and C. J. Glinka of the NIST Center for Neutron Research, for scientific and technical support, together with F. Kroupa of the Institute of Plasma Physics, Prague, and M. Kachanov of the Department of Mechanical Engineering, Tufts University, Medford, for valuable discussions. This research was supported, in part, by the National Science Foundation MRSEC Program at the State University of New York at Stony Brook under Grant No. 9632570 .

\section{REFERENCES}

1. Sivakumar, R. and Mordike, B. L., Surf. Coat. Technol., 1989, 37, 136.

2. Novak, R. C., Matarese, A. P., Huston, R. P. and Scharman, A. J., Mater. Manufactur. Processes, 1992, 7(1), 15.

3. Miller, R. A., J. Thermal Spray Technol., 1997, 6(1), 35.

4. Yonushonis, T. M., J. Thermal Spray Technol., 1997, 6(1), 50.

5. Grunling, H. W. and Mannsmann, W., J. Phys. IV, 1993, 3(C7), 903.

6. Miller, R. A., J. Am. Ceram. Soc., 1984, 67, 517.

7. Herman, H., Sci. Am., 1988, 259(3), 112.

8. Ilavsky, J. and Stalick, J. K., in Proc. 1st United Thermal Spray Conf., Indianapolis, USA. Thermal Spray: A United Forum for Scientific and Technological Advances, ed. C. C. Berndt. ASM Int, 1997, p. 691.

9. Hamsworth, P. D. and Stevens, R., J. Mater. Sci., 1992, 27, 616 .

10. Ibegazene, H., Alperine, S. and Diot, C., J. Mater. Sci., 1995, 30, 938 .

11. McPherson, R. and Shafer, B. V., Thin Solid Films, 1982, 97, 201.

12. Karthikeyan, J., in Proc. 14th Int. Thermal Spray Conf., Kobe, Japan. Thermal Spraying-Current Status and Future Trends, ed. A. Ohmori. High Temperature Society of Japan, 1995, p. 927.

13. Ilavsky, J., Berndt, C. C. and Karthikeyan, J., J. Mater. Sci., 1997, 32, 3925.

14. Ilavsky, J., Herman, H., Berndt, C. C., Goland, A. N., Long, G. G., Krueger, S. and Allen, A. J., in Proc. 7th Nat. Thermal Spray Conf., Boston, USA. Thermal Spray Industrial Applications, ed. C. C. Berndt and S. Sampath. ASM Int, 1994, p. 709.

15. Ilavsky, J., Allen, A. J., Long, G. G., Krueger, S., Herman, H., Berndt, C. C. and Goland, A. N., in Proc. 14th Int. Thermal Spray Conf., Kobe, Japan. Thermal SprayingCurrent Status and Future Trends, ed. A. Ohmori. High Temperature Society of Japan, 1995, p. 483.

16. Ilavsky, J., Long, G. G., Allen, A. J., Herman, H. and Berndt, C. C., in Proc. 9th Nat. Thermal Spray Conf., Cincinnati. Thermal Spray: Practical Solutions for Engineering Problems, ed. C. C. Berndt. ASM Int, 1996, p. 725.

17. Ilavsky, J., Allen, A. J., Long, G. G., Krueger, S., Berndt, C. C. and Herman, H., J. Am. Ceram. Soc., 1997, 80, 733.

18. Ilavsky, J., Allen, A. J., Long, G. G., Herman, H. and Berndt, C. C., J. Mater. Sci., 1997, 32, 3407.

19. Ilavsky, J., Long, G. G., Allen, A. J., Herman, H. and 
Berndt, C. C., in Proc. 1st United Thermal Spray Conf., Indianapolis. Thermal Spray: A United Forum for Scientific and Technological Advances, ed. C. C. Berndt. ASM Int, 1997, p. 697.

20. Ilavsky, J., Long, G. G. and Allen, A. J., in Proc. 15th Int. Thermal Spray Conf., Nice, France. Thermal Spray Meeting the Challenge of the 21st Century, ed. C. Coddet. ASM Int, 1998, p. 1641.

21. Ilavsky, J., Long, G. G., Allen, A. J., Prystay, M. and Moreau, C., in Proc. 15th Int. Thermal Spray Conf., Nice, France. Thermal Spray Meeting the Challenge of the 21st Century, ed. C. Coddet. ASM Int, 1998, p. 1577.

22. Ilavsky, J., Long, G. G., Allen, A. J. and Berndt, C. C., Mater. Sci. Eng. A., 1999, 272, 215.

23. Glinka, C. J., Rowe, J. M. and LaRock, J. G., J. Appl. Cryst., 1985, 19, 427.

24. Kostorz, G., in Treatise on Materials Science and Technology, Vol. 15, ed. G. Kostorz. Academic Press, New York, 1979, p. 227.

25. Porod, G., in Small-Angle X-ray Scattering, ed. O. Glatter and O. Kratky, Academic Press, New York, 1982, p. 17.

26. Hamzeh, F. M. and Bragg, R. H., J. Appl. Phys., 1974, 45, 3189 .

27. Wu, W., J. Polym. Sci.: Polym. Phys. Ed., 1980, 18, 1659.

28. Berk, N. F. and Hardman-Rhyne, K. A., J. Appl. Cryst., 1985, 18, 467.

29. Berk, N. F. and Hardman-Rhyne, K. A., Physica, 1986 , 136B, 218.

30. Berk, N. F. and Hardman-Rhyne, K. A., J. Appl. Cryst., 1988, 21, 645.

31. Allen, A. J. and Berk, N. F., J. Appl. Cryst., 1994, 27, 878.

32. Allen, A. J., Berk, N. F., Krueger, S., Long, G. G., Kerch, H. M. and Ilavsky, J., in Neutron Scattering in Materials Science II, MRS Proc. 376, ed. D. Neumann, T. Russell and B. Wuensch. Materials Research Society, 1995, p. 347.

33. Allen, A. J. and Berk, N. F., Neutron News, 1998, 9.2, 13 and 1999, 10.1, 26.

34. Hardman-Rhyne, K. A. and Berk, N. F., J. Appl. Cryst., 1985, 18, 473

35. Krueger, S., Long, G. G. and Page, R. A., Acta Cryst., 1991, A47, 282.

36. Long, G. G., Krueger, S., Gerhardt, R. A. and Page, R. A., J. Mater. Res., 1991, 6, 2706.

37. Roess, L. C. and Shull, C. G., J. Appl. Phys., 1947, 18, 308.

38. Oliver, W. C. and Pharr, G. M., J. Mater. Res., 1992, 7, 1564.

39. Wallace, J. S. and Ilavsky, J., in Proc. 1st United Thermal Spray Conf., Indianapolis. Thermal Spray: A United Forum for Scientific and Technological Advances, ed. C. C. Berndt. ASM Int, 1997, p. 757.

40. Leigh, S. -H., Lee, G-C. and Berndt, C. C., in Proc. 15th Int. Thermal Spray Conf., Nice, France. Thermal Spray Meeting the Challenge of the 21 st Century, ed. C. Coddet. ASM Int, 1998, p. 587.

41. Kachanov, M., Appl. Mech. Rev., 1992, 45, 304.

42. Kroupa, F. and Kachanov, M., in Proc. 19th Riso Int. Symp. on Mater. Sci., Rosskilde, Denmark. Modelling of Structure and Mechanics of Materials from Microscale to Product, Riso National Laboratory, Denmark, 1998, p. 325.

43. Sevostianov, I. and Kachanov, M., Acta mater., 2000, 48, 1361.

\section{APPENDIX A}

Summary of algebraic termsused

$\Phi, \Phi_{T} \quad$ Porosity: $\Phi$ may refer to one void component depending on the context; $\Phi_{T}$ refers to the total porosity and includes intrasplat cracks, intersplat pores and globular pores.

$\Phi_{C}, \Phi_{P}, \Phi_{G}$ Component porosities for the intrasplat cracks (C), intersplat pores (P) and globular pores $(\mathrm{G})$.

$S_{\mathrm{T}} \quad$ Total surface area per unit sample volume within all open and closed voids; includes intrasplat cracks, intersplat pores and globular pores. (Units in $10^{6}$ $\mathrm{m}^{-1}$ or $\mathrm{m}^{2} \mathrm{~cm}^{-3}$.)

$|\Delta \rho| \quad$ Difference in neutron scattering-length density between that in the solid, $\rho$, and that in the pores (zero). (Units in $10^{14}$ $\mathrm{m}^{-2}$, i.e., $\left.10^{14} \mathrm{~m} \mathrm{~m}^{-3}\right)$.

$|\Delta \rho|^{2} \quad$ Neutron scattering contrast. (Units in $10^{28} \mathrm{~m}^{-4}$.)

$2 \theta, \lambda, \tau_{\mathrm{s}} \quad$ Scattering angle, wavelength (units in $\mathrm{nm}$ ) and sample thickness (units in $\mathrm{m}$ or $\mathrm{mm})$, respectively.

$\mathbf{Q}, Q, k \quad$ Scattering vector $\mathbf{Q}$ with magnitude, $Q=4(\pi / \lambda) \sin \theta$, and a direction bisecting the incident and scattered beams, which each have wavevectors of magnitude, $k=2 \pi / \lambda$. (Units in $\mathrm{nm}^{-1}$.)

$\mathrm{d} \Sigma(\mathbf{Q}) / \mathrm{d} \Omega$ Absolute-calibrated single-scattering intensity or macroscopic differential scattering cross-section per unit sample volume. $\mathrm{d} \Sigma(\mathbf{Q}) / \mathrm{d} \Omega$ is the probability rate, per unit incident neutron flux and per unit sample volume, of scattering into unit solid angle, $\Omega$, about the scattered beam direction defined by the magnitude and direction of $\mathbf{Q}$. (Units in $\mathrm{m}^{-1}$ $\mathrm{sr}^{-1}$ or $\mathrm{cm}^{-1} \mathrm{sr}^{-1}$.) The function $\mathrm{d} \Sigma(\mathbf{Q}) / \mathrm{d} \Omega$ gives microstructural information along a particular direction of $\mathbf{Q}$ approximately perpendicular to the incident beam (see Fig. 1).

$R_{\mathrm{O}}, \beta \quad$ Radius (units in $\mu \mathrm{m}$ ) and corresponding oblate aspect ratio $(\beta \leq 1)$ of spheroidal crack or pore elements with orthogonal radii, $R_{\mathrm{O}}, R_{\mathrm{O}}$ and $\beta R_{\mathrm{O}}$. The intrasplat crack and intersplat pore void spaces are assumed to comprise separate networks of oblate spheroidal elements with mean radius and aspect ratio: $R_{\mathrm{OC}}$ and $\beta_{\mathrm{C}}$ for cracks, $R_{\mathrm{OP}}$ and $\beta_{\mathrm{P}}$ for intersplat pores. Globular pores are assumed to have their own mean radius, $R_{\mathrm{OG}}$.

$W\left(Q \mid \tau_{\mathrm{s}}\right) \quad$ Multiply-scattered neutron beam profile in $\mathbf{Q}$ emerging from a sample thickness, $\tau_{\mathrm{s}}$, normalized to the incident beam profile at $\tau_{\mathrm{s}}=0$. Hence, a dimensionless function of $\mathbf{Q}$. The double-differential of $W\left(Q \mid \tau_{\mathrm{s}}\right)$ in terms of $\mathbf{Q}$ is $W^{\prime \prime}\left(Q \mid \tau_{\mathrm{s}}\right)$ with units of $Q^{-2}$ or $\mathrm{nm}^{2}$.

$r_{\mathrm{c}} \quad$ Theoretically, the "radius of curvature" of the beam-profile $W\left(\mathbf{Q} \mid \tau_{\mathrm{s}}\right)$ in $\mathbf{Q}$ at $Q=0$. (Hence, units of $Q$ or $\mathrm{nm}^{-1}$ ). Experimentally, the measured beambroadening in $\mathbf{Q}$ (also with units of $Q$ or 
$\left.\mathrm{nm}^{-1}\right)$. For a Gaussian function fitted to the beam profile $W\left(\mathbf{Q} \mid \tau_{\mathrm{s}}\right)$ near $Q=0$, $r_{\mathrm{c}}$ is numerically equal to the standard deviation of the Gaussian.

$\bar{z} \quad$ The multiple scattering, i.e., the mean number of scattering events for each neutron passing through the sample.

$W\left(Q R_{\mathrm{O}} \mid \tau_{\mathrm{s}}\right) \quad$ Multiply-scattered circularly-symmetric neutron beam profile in $Q$ emerging from an axially-symmetric microstructure with scattering void size parameter, $R_{\mathrm{O}}$, and sample thickness, $\tau_{\mathrm{s}}$, normalized to the incident beam profile at $\tau_{\mathrm{s}}=0$.

$\zeta \quad$ Dimensionless integration parameter used in equation (3) to relate the beam profile, $W\left(Q R_{\mathrm{O}} \mid \tau_{\mathrm{s}}\right)$, to the real space function, $q(\zeta)$, which is defined in terms of the single-scattering cross-section per unit sample volume in equation (4).

$\left\langle\mathrm{d} \Sigma\left(Q, v_{\mathrm{O}}\right) /\right.$ Circularly-symmetric, absolute-cali$\mathrm{d} \Omega\rangle_{\text {ORIENT }}$ brated single-scattering intensity or differential scattering cross-section (at a given $Q$ ) per unit sample volume for a microstructure axially-symmetric about the incident beam direction. The orientational average is over the orientation distribution of the scattering voids with respect to the direction of $\mathbf{Q}$, and is the same for all axially-symmetric equivalent directions of $Q$. The effects of both diffraction and refraction are included. (Units in $\mathrm{m}^{-1} \mathrm{sr}^{-1}$.)

$\Sigma_{T}, \Sigma_{C}, \Sigma_{P}$, Total scattering cross-section per unit $\Sigma_{G} \quad$ sample volume: $\Sigma_{T}$ for all voids, $\Sigma_{C}$ for intrasplat cracks, $\Sigma_{P}$ for intersplat pores, and $\Sigma_{G}$ for globular pores, such that $\Sigma_{T}$ $=\Sigma_{C}+\Sigma_{P}+\Sigma_{G}$. (Units in $\mathrm{m}^{-1}$.)

$\sigma_{\mathrm{T}} \quad$ Average total scattering cross-section per scattering void (units: $10^{-28} \mathrm{~m}^{2}$ ) such that $\bar{z}=n \sigma_{\mathrm{T}} \tau_{\mathrm{s}}=\Sigma_{T} \tau_{\mathrm{s}}$, where $n$ is the number density of scatterers.

$v_{\mathrm{O}} \quad$ Dimensionless parameter for the phase shift between neutron de Broglie waves passing through a scattering void and around it: $v_{\mathrm{O}}=2 R_{\mathrm{O}}|\Delta \rho| \lambda$. Parameters, $v_{\mathrm{OC}}, v_{\mathrm{OP}}$ and $v_{\mathrm{OG}}$ give the phase shifts associated with intrasplat cracks (C), intersplat pores $(\mathrm{P})$ and globular pores (G) where $v_{\mathrm{OC}}=2 R_{\mathrm{OC}}|\Delta \rho| \lambda$ etc.

$K(\beta, X) \quad$ Orientational factor for a spheroid oriented with its $\beta R_{\mathrm{O}}$ axis at an angle $\eta$ with respect to $\mathbf{Q}$ and given by: $K(\beta, X)=$ $\left[1+\left(\beta^{2}-1\right) X^{2}\right]^{1 / 2}$ with $X=\cos (\eta)$.

$\mathrm{d} \Sigma_{\beta}\left(Q, v_{\mathrm{O}}\right)_{X}$ SANS cross-section for a spheroid of $/ \mathrm{d} \Omega \quad$ aspect ratio, $\beta$, and orientation, $X$, defined above, with scattering form-factor, $f_{\beta}\left(Q, v_{\mathrm{O}}\right)_{X}$.

Dimensionless integration parameter used in equation (5b) to define $f_{\beta}\left(Q, v_{\mathrm{O}}\right) X$ for single-scattering. (Not to be confused with $\zeta$ used in the derivation of $W\left(Q R_{\mathrm{O}} \mid \tau_{\mathrm{s}}\right)$ for multiple scattering.)

$\Sigma_{\beta, X}, \sigma_{\beta, X} \quad$ Total scattering cross-section per unit sample volume $\left(\Sigma_{\beta, X}\right)$ and per scattering void $\left(\sigma_{\beta, X}\right)$ for spheroids with aspect ratio, $\beta$, and orientation, $X$, defined above. $\sigma_{\beta, X}=\pi R_{\mathrm{O}}^{2} A(\beta, X)$ where $A(\beta, X)$ $=\mathrm{K}(\beta, X)\left\{2+\left(4 / \mathrm{c}^{2}\right)[1-\cos (c)-\right.$ $c \sin (c)]\}$ and $c=\beta v_{\mathrm{O}} / K(\beta, X)$.

$p_{\mathrm{L}}, p_{\mathrm{M}}, p_{\mathrm{H}}$ Probability weights-over-random of finding the short $\left(\beta R_{\mathrm{O}}\right)$ axes of the oblate spheroidal elements (the local crack- or pore-normals) within $30^{\circ}$ of the plasma spray direction, $30-60^{\circ}$ from the spray direction, or $60-90^{\circ}$ from it. Used to parameterize the separate approximate anisotropic orientation distributions of the intrasplat cracks and intersplat pores. $\langle$ O.D. Mean opening dimension for intrasplat cracks or intersplat pores. In each case, $\langle$ O.D. $\rangle=4 \beta R_{\mathrm{O}} / 3$.

Note that, $\bar{z}, W\left(Q R_{\mathrm{O}} \mid \tau_{\mathrm{s}}\right), q(\zeta),\left\langle\mathrm{d} \Sigma\left(Q, v_{\mathrm{O}}\right) / \mathrm{d} \Omega\right\rangle_{\text {ORIENT }}$, $\Sigma_{T}, \Sigma_{C}, \Sigma_{P}, \sigma_{\mathrm{T}}, p_{\mathrm{L}}, p_{\mathrm{M}}$, and $p_{\mathrm{H}}$ take different values for the two sample orientations shown in Fig. 1. Also note that, while sample orientation is defined with respect to the incident beam, individual spheroid orientation is defined with respect to $\mathbf{Q}$.

$E_{\mathrm{APP}}, E_{\mathrm{I}}, E_{\mathrm{S}}$ Elastic modulus from indentation measurements: measured apparent modulus, $E_{\mathrm{APP}}$, known indenter modulus, $E_{\mathrm{I}}$, and deduced modulus of sample perpendicular to the indented surface, $E_{\mathrm{S}}$. (Units in GPa.)

$\mu_{\mathrm{I}}, \mu_{\mathrm{S}} \quad$ Assumed Poisson's ratios for the indenter $\left(\mu_{\mathrm{I}}\right)$ and the sample $\left(\mu_{\mathrm{S}}\right)$ in indentation measurements.

$E_{\mathrm{PLANE}}$, Elastic modulus within the substrate

$\mathrm{E}_{\mathrm{SPRAY}}, E_{\mathrm{O}}$ plane $\left(E_{\mathrm{PLANE}}\right)$ and along the spray direction $\left(E_{\text {SPRAY }}\right)$ of the plasma-sprayed deposits as deduced from indentation measurements. $E_{\mathrm{O}}$ is Young's modulus for fully-dense zirconia (210 GPa).

$\alpha_{\mathrm{C}}, \alpha_{\mathrm{P}} \quad$ Mean macroscopic intrasplat-crack $\left(\alpha_{\mathrm{C}}\right)$ and intersplat-pore $\left(\alpha_{\mathrm{P}}\right)$ aspect ratios, defined as the ratio of the $\langle$ O.D. $\rangle$ to the mean "penny" diameter for each component. Penny diameter take as mean large planar dimension for each void component, traced through any tortuosity present.

$d_{\mathrm{C}}, d_{\mathrm{P}} \quad$ Scalar densities of intrasplat cracks $\left(d_{\mathrm{C}}\right)$ and intersplat pores $\left(d_{\mathrm{P}}\right)$ defined by: $d_{\mathrm{C}}$ $=\Phi_{C}\left(4 \pi \alpha_{\mathrm{C}} / 3\right)$ and $d_{\mathrm{P}}=\Phi_{P} /\left(4 \pi \alpha_{\mathrm{P}} / 3\right)$. 